\title{
Syntrophism Among Prokaryotes
}

\author{
Bernhard Schink ${ }^{1}$. Alfons J. M. Stams ${ }^{2}$ \\ ${ }^{1}$ Department of Biology, University of Konstanz, Constance, Germany \\ ${ }^{2}$ Laboratory of Microbiology, Wageningen University, Wageningen, The Netherlands
}

\section{Introduction: Concepts of Cooperation in Microbial \\ Communities, Terminology}

Electron Flow in Methanogenic and Sulfate-Dependent

Degradation .................................. 472

Energetic Aspects ............................. 473

Degradation of Amino Acids ...................... 474

Influence of Methanogens ........................4 475

Obligately Syntrophic Amino Acid Deamination ....... 475

Syntrophic Arginine, Threonine, and Lysine

Fermentation .................................475

Facultatively Syntrophic Growth with Amino Acids ....476

Stickland Reaction Versus Methanogenesis ...........477

\section{Syntrophic Degradation of Fermentation}

Intermediates

Syntrophic Ethanol Oxidation .....................477

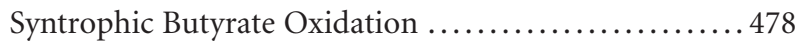

Syntrophic Propionate Oxidation ................... 480

Syntrophic Acetate Oxidation ......................448

Syntrophic Glycolate Oxidation ....................4 481

Syntrophic Oxidation of Aromatic Compounds ....... 481

Syntrophic Oxidation of Branched Chain

Fatty Acids

Fermentation of Acetone

Interspecies Metabolite Transfer

Anaerobic Methane Oxidation 484

“Obligately Syntrophic” Bacteria: Cultivation and Biochemical Studies 484

Homoacetogenic Versus Methanogenic Coupling and the Effect of Temperature 485

Structure and Growth Dynamics of

Syntrophic Associations

Cooperation with Protozoa, Hydrogenosomes 487

Taxonomy of Syntrophs 488

Conclusions 488

\section{Introduction: Concepts of Cooperation in Microbial Communities, Terminology}

The study of pure cultures in the laboratory has provided an amazingly diverse diorama of metabolic capacities among microorganisms and has established the basis for our under standing of key transformation processes in nature. Pure culture studies are also prerequisites for research in microbial biochem istry and molecular biology. However, desire to understand how microorganisms act in natural systems requires the realization that microorganisms do not usually occur as pure cultures out there but that every single cell has to cooperate or compete with other micro or macroorganisms. The pure culture is, with some exceptions such as certain microbes in direct cooperation with higher organisms, a laboratory artifact. Information gained from the study of pure cultures can be transferred only with great caution to an understanding of the behavior of microbes in natural communities. Rather, a detailed analysis of the abiotic and biotic life conditions at the microscale is needed for a correct assessment of the metabolic activities and requirements of a microbe in its natural habitat.

Most aerobic bacteria can degrade even fairly complex sub strates to water and carbon dioxide without any significant coop eration with other organisms. Nutritional cooperation may exist but may be restricted to the transfer of minor growth factors, such as vitamins, from one organism to the other. However, we have to realize that this assumption is based on experience gained from pure cultures that were typically enriched and isolated in simple media, and the selection aimed at organisms that were easy to handle, independent of possible interactions with others. Estima tions assume that we know only a small fraction of the microor ganisms present in nature, perhaps $0.11 .0 \%$. Thus, we cannot exclude that other bacteria out there might depend to a large extent on cooperation with partner microbes, and perhaps this is just one of the reasons why we failed so far to isolate them.

Anaerobic microorganisms, on the other hand, depend to a great extent on the cooperation of several metabolic types of bacteria in feeding chains. The complete conversion of complex organic matter, e.g., cellulose, to methane and carbon dioxide in a lake sediment is catalyzed by the concerted action of at least four different metabolic groups of bacteria, including primary fermenters, secondary fermenters, and at least two types of methanogenic archaea (Bryant 1979; McInerney 1988; Stams 1994; Schink 1991, 1997; Stams and Plugge 2009). The degree of mutual dependence among these different metabolic groups ("functional guilds") can vary considerably; whereas the latter 
members in the feeding line always depend on the former ones for substrate supply, they may also influence significantly the former chain members by removal of metabolic products. In an extreme case, this can mean that the fermenting bacterium depends entirely on cooperation with a methanogen to fulfill its function in, e.g., methanogenic fatty acid oxidation. This type of cooperation is called "syntrophic."

Mutual metabolic dependencies also can emerge from the cooperation of phototrophs with sulfur or sulfate reducing bacteria. Sulfur reducing, acetate oxidizing, chemotrophic bac teria such as Desulfuromonas acetoxidans and phototrophic green sulfide oxidizing bacteria like Chlorobium sp. can cooper ate closely in a phototrophic conversion of acetate plus $\mathrm{CO}_{2}$ to bacterial cell mass using a sulfide/sulfur cycle as an electron shuttle system between both. The two partners cooperate very closely also in this system for which the term "syntrophy" was originally coined (Biebl and Pfennig 1978).

Syntrophy is a special case of symbiotic cooperation between two metabolically different types of bacteria which depend on each other for degradation of a certain substrate, typically through transfer of one or more metabolic intermediate(s) between the partners. The pool size of the shuttling intermediate has to be kept low to allow efficient cooperation.

The term "syntrophy" should be restricted to those cooper ations in which partners depend on each other to perform the metabolic activity observed and in which the mutual depen dence cannot be overcome by simply adding a cosubstrate or any type of nutrient. A classical example is the Methanobacillus omelianskii culture (Barker 1940), which was later shown to be a coculture of two partner organisms, the $S$ strain and the strain M.o.H. (Bryant et al. 1967). Both strains cooperate in the conversion of ethanol to acetate and methane by interspecies hydrogen transfer, as follows:

\section{Strain S:}

$$
\begin{gathered}
2 \mathrm{CH}_{3} \mathrm{CH}_{2} \mathrm{OH}+2 \mathrm{H}_{2} \mathrm{O} \rightarrow 2 \mathrm{CH}_{3} \mathrm{COO}+2 \mathrm{H}^{+}+4 \mathrm{H}_{2} \\
\Delta \mathrm{G}_{0}{ }^{\prime}=+19 \mathrm{~kJ} \text { per } 2 \mathrm{~mol} \text { of ethanol }
\end{gathered}
$$

\section{Strain M.o.H.}

$$
\begin{aligned}
& 4 \mathrm{H}_{2}+\mathrm{CO}_{2} \rightarrow \mathrm{CH}_{4}+2 \mathrm{H}_{2} \mathrm{O} \\
& \qquad \mathrm{G}_{0}{ }^{\prime}=-131 \mathrm{~kJ} \text { per mol of methane } \\
& \text { Coculture: } \\
& 2 \mathrm{CH}_{3} \mathrm{CH}_{2} \mathrm{OH}+\mathrm{CO}_{2} \rightarrow 2 \mathrm{CH}_{3} \mathrm{COO}+3 \mathrm{H}^{+}+\mathrm{CH}_{4} \\
& \Delta \mathrm{G}_{0}{ }^{\prime}=-112 \mathrm{~kJ} \text { per mol of methane }
\end{aligned}
$$

Thus, the fermenting bacterium cannot be grown with ethanol in the absence of the hydrogen scavenging partner organism because it carries out a reaction that is endergonic under standard conditions. The first reaction can occur and provide energy for the first strain only if the hydrogen partial pressure is kept low enough $\left(>10^{-3}\right.$ bar) by the methanogen. Therefore, neither partner can grow with ethanol alone, and the degradation of ethanol depends on the cooperating activities of both.

We avoid in this article the term "consortium" which is quite often used to describe any kind of enrichment cultures cooperating in whatever way. This term was originally coined for the structured phototrophic aggregates Pelochromatium and Chlorochromatium, etc., and should be restricted to such spa tially well organized systems (Pfennig 1980; Overmann 2002).

\section{Electron Flow in Methanogenic and Sulfate-Dependent Degradation}

The degradation of complex organic matter to methane and $\mathrm{CO}_{2}$ is a process widespread in anoxic environments which receive only a limited supply of oxygen, nitrate, sulfate, or oxidized iron or manganese species. Methanogenesis is the typ ical terminal electron accepting process in freshwater sediments rich in organic matter, in swamps or waterlogged soils such as rice paddies, or in anaerobic wastewater and sewage treatment plants. It is also an important process in fermentations occurring in the intestinal tract of animals, especially of ruminants. Methanogenic degradation is the least exergonic process in comparison to aerobic degradation or the alternative anaerobic respiration. Conversion of hexose to methane and carbon dioxide releases only $15 \%$ of the energy that would be available in aerobic degradation, and this small energy yield of methanogenic degradation may be the reason why methanogenesis is the last one to occur, after the other electron acceptors have been reduced.

The carbon and electron flow in methanogenic degradation of complex organic matter follows a rather simple pattern. Poly mers (polysaccharides, proteins, nucleic acids, and also lipids) are first converted to oligo and monomers (sugars, amino acids, purines, pyrimidines, fatty acids, and glycerol), typically through the action of extracellular hydrolytic enzymes. These enzymes are produced by the "classical" primary fermenting bacteria which ferment the monomers further to fatty acids, branched chain fatty acids, succinate, lactate, alcohols, aromatic acids, etc. (group 1; $\boldsymbol{\nabla}$ Fig. 21.1). Some of these fermentation products, such as acetate, $\mathrm{H}_{2}, \mathrm{CO}_{2}$, and other one carbon com pounds, can be used directly by methanogens which convert them to methane and carbon dioxide (groups 2 and 3; ( Fig. 21.1). For methanogenic degradation of other fermenta tion products, e.g., fatty acids longer than two carbon atoms, alcohols longer than one carbon atom, branched chain and aromatic fatty acids, a further group of fermenting bacteria, the so called secondary fermenters or obligate proton reducers (group 4; $>$ Fig. 21.1), is needed. These bacteria convert their substrates to acetate, carbon dioxide, hydrogen, perhaps also formate, which are subsequently used by the methanogens.

The situation is slightly different in sulfate rich anoxic hab itats such as marine sediments. There, the primary processes of polymer degradation are carried out by primary fermenting bacteria which form the classical fermentation products. Differ ent from methanogens, sulfate reducing bacteria are metaboli cally versatile, and a broad community of sulfate reducers can use all products of primary fermentations, and oxidize them to carbon dioxide, simultaneously reducing sulfate to sulfide (Widdel 1988). As a consequence, the complete oxidation of 


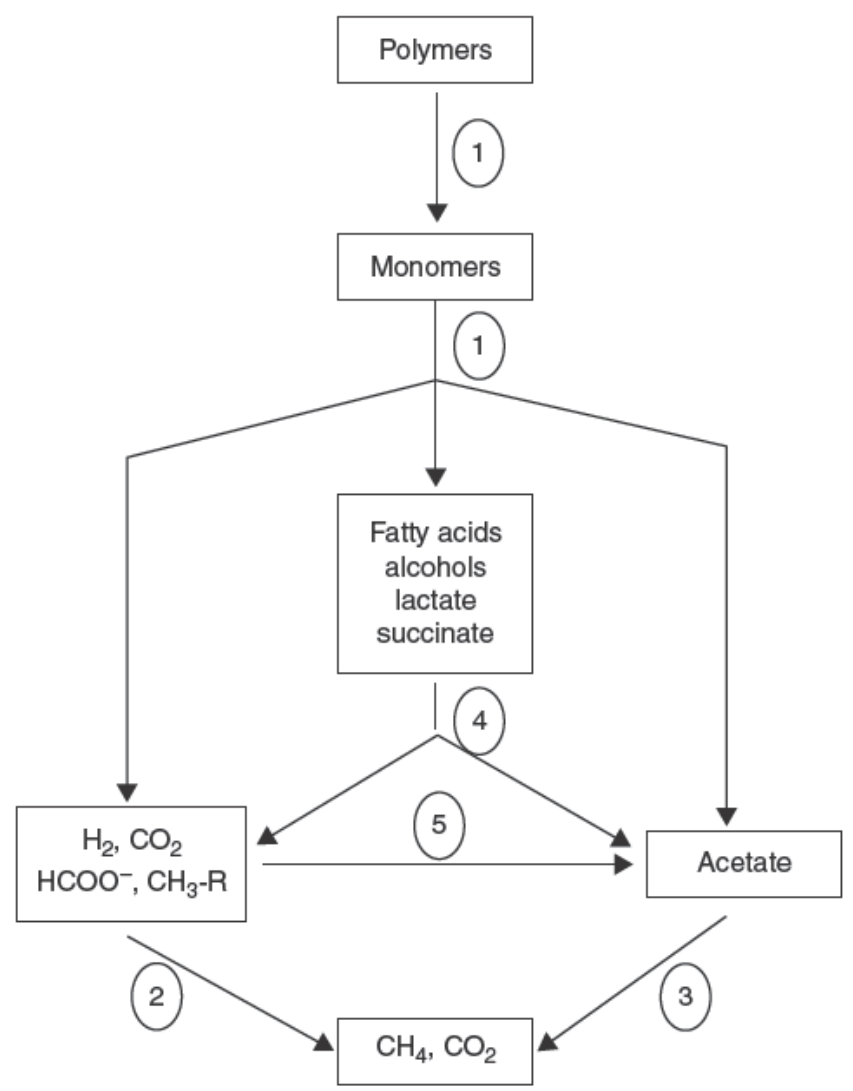

D Fig. 21.1

Carbon and electron flow in the methanogenic degradation of complex organic matter. Groups of prokaryotes involved 1 primary fermentative bacteria, 2 hydrogen-oxidizing methanogens, 3 acetate-cleaving methanogens, 4 secondary fermenting bacteria (syntrophs), and 5 homoacetogenic bacteria

complex organic matter to carbon dioxide with simultaneous sulfate reduction proceeds in a two step process and does not depend on syntrophic fermentations. One might add that this two step scheme might be augmented also by cooperative sidepaths taken by different types of sulfate reducing bacteria, e.g., completely and incompletely oxidizing ones (Widdel and Hansen 1991), but such cooperative activities are not required for complete sulfate dependent oxidation of organic matter.

In methanogenic and sulfate rich environments, the pri mary fermenting bacteria (group 1) profit from the activities of the hydrogen oxidizing partners at the end of the degradation chain as well. A low hydrogen partial pressure $\left(<10^{-4}\right.$ bar $)$ allows electrons at the redox potential of NADH $(-320 \mathrm{mV})$ to be released as molecular hydrogen, and fermentation patterns can shift to more acetate, $\mathrm{CO}_{2}$, and hydrogen production rather than to ethanol or butyrate formation, thus allowing additional ATP synthesis via substrate level phosphorylation, as opposed to production of reduced fermentation products (ethanol, lactate, and butyrate). Thus, such fermenting bacteria may profit from hydrogen oxidizing partners, but they do not depend on such cooperation.
In a well balanced anoxic sediment in which an active hydrogen utilizing community maintains a low hydrogen par tial pressure, the flux of carbon and electrons goes nearly exclu sively through the "outer" paths of the electron flow scheme (- Fig. 21.1), and therefore reduced fermentation intermediates play only a minor role. Recently a novel bacterium was described which ferments even sugars exclusively to acetate, $\mathrm{CO}_{2}$, and hydrogen and depends for this process on a cooperation with methanogenic partners (Müller et al. 2008). Nonetheless, the flux through the "central" paths will never become zero because long chain and branched chain fatty acids and others are always produced in the fermentation of lipids and amino acids as well. The reduced intermediates of the central path become more important if the hydrogen pool increases for any reason, e.g., excess supply of fermentable substrate, inhibition of hydrogenotrophic methanogens due to a drop in $\mathrm{pH}(<6.0)$, or to the presence of toxic compounds, etc. Under such condi tions, the pools of fatty acids increase and might even shift the $\mathrm{pH}$ further downward, thus inhibiting the hydrogenotrophic methanogens even further. The consequence may be that the whole system "turns over," meaning that methanogenesis ceases entirely and the fermentation stops with accumulation of huge amounts of foul smelling fatty acids, as this is encountered with ill balanced anaerobic sewage digestors. Obviously, the hydro gen/formate utilizing methanogens act as the primary regula tors in the total methanogenic conversion process (Bryant 1979; Zehnder 1978; Zehnder et al. 1982), and the syntrophically fatty acid oxidizing bacteria are affected most severely by a failure in methanogenic hydrogen or formate removal.

The function of homoacetogenic bacteria (group 5; ( $)$ Fig. 21.1) in the overall process is less well understood. They connect the pool of one carbon compounds and hydrogen with that of acetate. Owing to their metabolic versatility, they can participate also in sugar fermentation and degradation of special substrates such as $N$ methyl compounds or methoxylated phe nols (Schink 1994). In certain environments, e.g., at lower $\mathrm{pH}$ or low temperature, they may even successfully compete with hydrogenotrophic methanogens and take over their function to a varying extent (see below).

\section{Energetic Aspects}

Anaerobes grow with small amounts of energy, and syntrophically cooperating anaerobes are extremely skilled in the exploitation of minimal energy spans. Synthesis of ATP as the general currency of metabolic energy in living cells requires $+32 \mathrm{~kJ}$ per mol at equilibrium under standard conditions; under the conditions assumed to prevail in an actively growing cell $\left([\mathrm{ATP}]=10 \mathrm{mM} ;[\mathrm{ADP}]=1 \mathrm{mM}\right.$; and $\left.\left[\mathrm{P}_{\mathrm{i}}\right]=10 \mathrm{mM}\right),+49 \mathrm{~kJ}$ per mol is required (Thauer et al. 1977). In addition, part of the total energy budget is always lost in irreversible reaction steps as heat, thus rendering the overall metabolic process irreversible. This heat loss (on average about $20 \mathrm{~kJ}$ per mol ATP) has to be added to the above value, which gives a total of about $70 \mathrm{~kJ}$ per mol ATP synthesized irreversibly in the living cell. This is the 
minimum amount of energy required for the synthesis of one mol of ATP in all known metabolic systems (Schink 1990). One may argue that (especially under conditions of energy limitation) an organism may waste less energy in heat production or that it may operate at an energy charge considerably lower than that quoted above for well growing Escherichia coli cells. Nonetheless, one cannot expect the energy requirement for irreversible ATP synthesis to go substantially below about $+60 \mathrm{~kJ}$ per mol.

The key postulate of the Mitchell theory of respirative ATP synthesis is that ATP formation is coupled to a vectorial transport of charged groups, typically protons, across a semipermeable membrane (Mitchell 1966). For several years, it was widely accepted that three protons cross the membrane (either of bacteria or mitochondria) per ATP hydrolyzed. As a consequence, the smallest quantum of metabolically convert ible energy is that of an ion transported across the cytoplasmic membrane, equivalent to one third of an ATP unit. Combined with the calculations above, this means that a bacterium needs a minimum of about $-20 \mathrm{~kJ}$ per mol reaction to exploit a reaction's free energy change (Schink and Thauer 1988; Schink 1990).

On the basis of studies on the structure and function of $\mathrm{F}_{1} \mathrm{~F}_{0}$ ATPases in recent years, the stoichiometry of ATP synthesis versus proton translocation appears not to be as strictly fixed as suggested above. Rather, the system may operate like a sliding clutch, meaning that at very low energy input, the energy trans fer into ATP synthesis may be substoichiometric. Moreover, the stoichiometry is not necessarily three protons per one ATP but is governed by the number of subunits arranged in the $F_{0}$ versus the $\mathrm{F}_{1}$ complex. This concept would allow also stoichiometries of 4:1, perhaps even 5:1 (Engelbrecht and Junge 1997; Cherepanov et al. 1999; Stock et al. 1999; Dimroth 2000; Seelert et al. 2000; von Ballmoos et al. 2009). As a consequence, the minimum energy increment that can still be used for ATP synthesis may be as low as -15 or $-12 \mathrm{~kJ}$ per mol reaction. In some cases, to make their living, bacteria cooperating in syntrophic fermenta tions are limited to this range of energy; Hoehler et al. (2001) calculated from metabolite concentrations in natural habitats for the partner bacteria cooperating in syntrophic conversions minimum amounts of exploitable energy in the range of -10 to $-19 \mathrm{~kJ}$ per mol reaction.

\section{Degradation of Amino Acids}

During protein hydrolysis, a complex mixture of amino acids and small peptides is produced. These amino acids and peptides can serve as energy substrates for anaerobic microorganisms. Detailed information on the anaerobic fermentation of amino acids can be found in Barker (1981) and McInerney (1988). Many anaerobic amino acid degrading bacteria require complex mixtures of amino acids, perhaps because a one sided diet causes a serious imbalance in the internal amino acid metabo lism of these cells, but growth by fermentation of single amino acids is also common. Mixtures of amino acids are often degraded by coupled fermentation of pairs of amino acids via
- Table 21.1

Changes of Gibbs free energies under standard conditions in hydrogen-releasing reactions during fermentation of amino acids

\begin{tabular}{|c|c|}
\hline Fermentation reaction & $\begin{array}{l}\Delta \mathrm{G}_{0}^{\prime}(\mathrm{kJ} \text { per mol } \\
\text { rct.) }\end{array}$ \\
\hline Alanine $+2 \mathrm{H}_{2} \mathrm{O} \rightarrow$ acetate $^{-}+\mathrm{CO}_{2}+\mathrm{NH}_{4}^{+}+2 \mathrm{H}_{2}$ & +2.7 \\
\hline Glycine $+2 \mathrm{H}_{2} \mathrm{O}+\mathrm{H}^{+} \rightarrow 2 \mathrm{CO}_{2}+\mathrm{NH}_{4}^{+}+3 \mathrm{H}_{2}$ & +17.8 \\
\hline Serine $+\mathrm{H}_{2} \mathrm{O} \rightarrow$ acetate $^{-}+\mathrm{CO}_{2}+\mathrm{NH}_{4}^{+}+\mathrm{H}_{2}$ & $85.3^{\mathrm{a}}$ \\
\hline $\begin{array}{l}\text { Threonine }+\mathrm{H}_{2} \mathrm{O} \rightarrow \text { propionate }^{-}+\mathrm{CO}_{2}+ \\
\mathrm{NH}_{4}^{+}+\mathrm{H}_{2}\end{array}$ & $83.0^{\mathrm{a}}$ \\
\hline $\begin{array}{l}\text { Histidine }+4 \mathrm{H}_{2} \mathrm{O}+\mathrm{H}^{+} \rightarrow \text { glutamate }^{-}+\mathrm{CO}_{2}+ \\
2 \mathrm{NH}_{4}^{+}+\mathrm{H}_{2}\end{array}$ & b \\
\hline Proline $+2 \mathrm{H}_{2} \mathrm{O} \rightarrow$ glutamate ${ }^{-}+\mathrm{H}^{+}+2 \mathrm{H}_{2}$ & b \\
\hline $\begin{array}{l}\text { Glutamate }^{-}+2 \mathrm{H}_{2} \mathrm{O}+\mathrm{H}^{+} \rightarrow \text { propionate }^{-}+ \\
2 \mathrm{CO}_{2}+\mathrm{NH}_{4}^{+}+2 \mathrm{H}_{2}\end{array}$ & 16.6 \\
\hline $\begin{array}{l}\text { Glutamate }^{-}+2 \mathrm{H}_{2} \mathrm{O} \rightarrow 2 \text { acetate }^{-}+\mathrm{CO}_{2}+ \\
\mathrm{NH}_{4}^{+}+\mathrm{H}_{2}\end{array}$ & $38.6^{\mathrm{a}}$ \\
\hline $\begin{array}{l}\text { Aspartate }{ }^{-}+2 \mathrm{H}_{2} \mathrm{O}+\mathrm{H}^{+} \rightarrow \text { acetate }^{-}+2 \mathrm{CO}_{2}+ \\
\mathrm{NH}_{4}^{+}+2 \mathrm{H}_{2}\end{array}$ & 24.1 \\
\hline
\end{tabular}

All calculations are based on published tables (see Thauer et al. 1977; Dimroth 1983). For $\mathrm{H}_{2} \mathrm{~S}$ and $\mathrm{CO}_{2}$, values for the gaseous state were used ${ }^{a}$ These fermentations may also allow growth in pure culture

${ }^{\mathrm{b}}$ These reactions are always coupled to further fermentation of glutamate

the Stickland reaction. (- Table 21.1 summarizes some oxidative conversions of amino acids. In the classical Stickland fermenta tion, these oxidation reactions are coupled within the same organism to reduction of other amino acids such as glycine or proline. Also phenylalanine, leucine, or compounds like sarcosine and betaine (Naumann et al. 1983; Gottschalk 1986) can act as electron acceptors, and oxidation of leucine coupled to the reduction of acetate to butyrate has been described as well (Girbal et al. 1997).

These pure culture fermentations can also be catalyzed by cooperation of two different bacteria via interspecies hydrogen transfer according to the following reactions with a mixture of alanine and glycine:

$$
\begin{aligned}
& \mathrm{CH}_{3} \mathrm{CH}\left(\mathrm{NH}_{3}^{+}\right) \mathrm{COO}^{-}+2 \mathrm{H}_{3} \mathrm{O} \rightarrow \mathrm{CH}_{3} \mathrm{COO}^{-}+\mathrm{CO}_{2}+\mathrm{NH}_{4}^{+}+2 \mathrm{H}_{2} \\
& \Delta \mathrm{G}_{0}{ }^{\prime}=+27 \mathrm{~kJ} \text { per mol } \\
& \mathrm{CH}_{2}\left(\mathrm{NH}_{3}^{+}\right) \mathrm{COO}^{-}+\mathrm{H}_{2} \rightarrow \mathrm{CH}_{3} \mathrm{COO}^{-}+\mathrm{NH}_{4}^{+} \\
& \Delta \mathrm{G}_{0}{ }^{\prime}=78 \mathrm{~kJ} \text { per mol } \\
& \mathrm{CH}_{3} \mathrm{CH}\left(\mathrm{NH}_{3}^{+}\right) \mathrm{COO}^{-}+2 \mathrm{CH}_{2}\left(\mathrm{NH}_{3}^{+}\right) \mathrm{COO}^{-}+2 \mathrm{H}_{2} \mathrm{O} \rightarrow 3 \mathrm{CH}_{3} \mathrm{COO}^{-} \\
& +\mathrm{CO}_{2}+3 \mathrm{NH}_{4}^{+} \\
& \Delta \mathrm{G}_{0}{ }^{\prime}=153 \mathrm{~kJ} \text { per mol }
\end{aligned}
$$

Thus, the electrons derived in amino acid degradation by a fermenting bacterium can be used in glycine reduction as shown but can be transferred as well in the form of molecular hydrogen to sulfate reducing, homoacetogenic, or methanogenic partner bacteria, depending on the availability of such partner bacteria and their respective electron acceptors. That amino acid oxidation and glycine reduction can be uncoupled from each other has been shown in detail with Eubacterium 
acidaminophilum (Zindel et al. 1988). This bacterium can run either one of the first two reactions separately or combine them on its own, according to the third reaction, depending on the partner bacteria which act as hydrogen sources or sinks, and on the availability of selenium in the medium which is required for expression of the active glycine reductase complex.

In methanogenic environments, methanogens can act as scavengers of reducing equivalents in the oxidation of amino acids, thus taking over the role of the reductive part of the Stickland reaction. Nagase and Matsuo (1982) observed that in mixed methanogenic communities, the degradation of alanine, valine, and leucine was inhibited when methanogens were inhibited. Nanninga and Gottschal (1985) could stimulate the degradation of these amino acids by addition of hydrogen scavenging sulfate reducers. These early observations indicated a functional role for hydrogen consumption also in the degra dation of amino acids.

\section{Influence of Methanogens}

Methanogens can affect anaerobic oxidation in various ways. Fermentative oxidation of some amino acids can be coupled to hydrogen formation only if the hydrogen partial pressure is kept low, similar to the Methanobacillus omelianskii example described above. This results in an obligately syntrophic rela tionship between the fermenting microorganism and the methanogen. Some amino acids are degraded by the same fermenting bacterium either in pure culture or in mixed culture with methanogens; however, methanogens can cause a shift in metabolism resulting in a changed product formation pattern.

Clostridium sporogenes (Wildenauer and Winter 1986; Winter et al. 1987), Eubacterium acidaminophilum (Zindel et al. 1988), Acidaminobacter hydrogenoformans (Stams and Hansen 1984), Aminomonas paucivorans (Baena et al. 1999a), Aminobacterium colombiense, and Aminobacterium mobile (Baena et al. 1998, 2000), as well as strain PA 1 (Barik et al. 1985), are mesophilic bacteria which degrade one or more amino acids in syntrophic association with hydrogen consuming anaerobes. Moderately thermophilic bacteria include Caloramator coolhaasii (Plugge et al. 2000), Caloramator proteoclasticus (Tarlera et al. 1997; Tarlera and Stams 1999), Thermanaerovibrio acidaminovorans (previously named Selenomonas acidaminovorans; Cheng et al. 1992; Baena et al. 1999b), Gelria glutamica (Plugge et al. 2002), and Clostridium P2 (Ørlygsson et al. 1993; Ørlygsson 1994). There are probably many other fermenting bacteria with the ability to grow syntrophically with certain amino acids and to release reducing equivalents as molecular hydrogen; however, such capacities are only rarely checked.

\section{Obligately Syntrophic Amino Acid Deamination}

The initial step in the oxidative degradation of alanine, valine, leucine, and isoleucine is an $\mathrm{NAD}(\mathrm{P})$ dependent deamination to the corresponding $\alpha$ keto acid, and the reaction, if coupled to reoxidation of $\mathrm{NAD}(\mathrm{P}) \mathrm{H}$ by proton reduction, would read as follows:

$$
\mathrm{RCH}\left(\mathrm{NH}_{4}^{+}\right) \mathrm{COO}+\mathrm{H}_{2} \mathrm{O} \rightarrow \mathrm{RCOCOO}+\mathrm{NH}_{4}^{+}+\mathrm{H}_{2}
$$

The $\Delta \mathrm{G}_{0}{ }^{\prime}$ of this reaction is about $+55 \mathrm{~kJ}$ per mol; thus, very efficient hydrogen consumption would be required to pull this reaction. The $\alpha$ keto acid is converted further via oxidative decarboxylation to a fatty acid:

$$
\mathrm{RCOCOO}+\mathrm{H}_{2} \mathrm{O} \rightarrow \mathrm{RCOO}+\mathrm{CO}_{2}+\mathrm{H}_{2}
$$

a reaction which is much more favorable $\left(\Delta \mathrm{G}_{0}{ }^{\prime}\right.$ about $-52 \mathrm{~kJ}$ per $\mathrm{mol}$ ). Therefore, it is not surprising that one does not observe bacteria catalyzing the first reaction step only and that the organisms involved as far as they have been tested can grow in pure culture with $\alpha$ keto acids. Such $\alpha$ keto acids were used successfully for the isolation of amino acid degrading proton reducing bacteria (Stams and Plugge 1990). Conversion of the keto acids to the corresponding fatty acids likely proceeds through energy rich CoA and phosphate derivatives, thus allowing ATP synthesis via substrate level phosphorylation.

Eubacterium acidaminophilum degrades aspartate to acetate in syntrophic association with methanogens (Zindel et al. 1988). The degradation pathway is not known. Aspartate is either oxidized directly to oxaloacetate by means of an aspartate dehy drogenase or is degraded first to fumarate by aspartase activity. Fumarate is then converted to malate which is subsequently oxidized to oxaloacetate. In this pathway, the conversion of malate to oxaloacetate plus $\mathrm{H}_{2}$ is most unfavorable; the $\Delta \mathrm{G}_{0}{ }^{\prime}$ is +48 kJ per mol. Recently, a moderately thermophilic sugar fermenting bacterium, Gelria glutamica, was isolated which can grow also by the analogous conversion of glutamate to propionate, provided that the hydrogen partial pressure is kept low by a methanogen (Plugge et al. 2002). In this bacterium, glutamate is first oxidatively deaminated to $\alpha$ ketoglutarate, which is subsequently oxidatively decarboxylated to succinyl CoA and further to propionate (Plugge et al. 2001). In coculture with methanogens, it is also able to oxidize proline to propio nate. This is remarkable because proline is generally thought to be reductively degraded to aminovalerate. Similar to the above mentioned amino acids, the aromatic amino acids phenylala nine, tryptophan, and tyrosine might also support growth by oxidative deamination leading to phenylacetate, indolylacetate, $p$ hydroxyphenylacetate, respectively, as products. This, how ever, has not yet been demonstrated for syntrophic amino acid degrading bacteria.

\section{Syntrophic Arginine, Threonine, and Lysine Fermentation}

Acidaminobacter hydrogenoformans, Aminomonas paucivorans, and T. acidaminovorans can grow with histidine, ornithine, arginine, lysine, and threonine when cocultured with hydrogenotrophic bacteria (Stams and Hansen 1984; Cheng et al. 1992; Baena et al. 1999a). Remarkably, T. acidaminovorans 
and A. paucivorans grow in pure culture with arginine, forming citrulline and/or ornithine as products. In this conversion, carbamyl phosphate is formed as an intermediate, which is further converted to yield ATP (Plugge and Stams 2001). Orni thine and citrulline could be degraded when these bacteria were cocultured with a hydrogenotrophic methanogen. It is not clear which pathway is used for ornithine degradation and which metabolic step is hampering growth of these bacteria in pure culture.

Acidaminobacter hydrogenoformans degrades threonine and lysine in syntrophic association with a hydrogen consuming anaerobe. Acetate is the main product of the degradation of these two amino acids, and large amounts of hydrogen are formed. In pure culture, these compounds do not support growth. The stoichiometry of the fermentation is not exactly known, and the pathways involved in these fermentations have not been resolved as yet.

Also the biogenic amine cadaverine (the decarboxylation product of lysine) can be degraded to methane and $\mathrm{CO}_{2}$ through a syntrophic association (Roeder and Schink 2009). Degradation is initiated by transamination with 2 oxoglutarate and proceeds via oxidation to a glutaryl residue.

\section{Facultatively Syntrophic Growth with Amino Acids}

The effect of methanogens on the metabolism of amino acid fermenting anaerobes has been studied most extensively with glutamate. Glutamate fermentation is carried out by a variety of fastidious anaerobes, including a number of Clostridium species, Peptostreptococcus asaccharolyticus, and Acidaminococcus fermentans (Gottschalk 1986). These microorganisms ferment glutamate to acetate and butyrate by two different pathways, the $\beta$ methylaspartate or the hydroxyglutarate pathway (Buckel and Barker 1974). In this fermentation, reducing equivalents formed in the oxidation of glutamate to acetate are disposed of either partly or completely by reductive formation of butyrate from acetate (acetyl CoA).

Anaeromusa acidaminophila (Selenomonas acidaminophila) ferments glutamate to acetate plus propionate (Nanninga et al. 1987; Baena et al. 1999b). In this bacterium, reducing equivalents are disposed of by reduction of pyruvate to propio nate. However, in the last decade, several bacteria have been isolated which during growth on glutamate release reducing equivalents exclusively as hydrogen, both in the formation of acetate and the formation of propionate (\$ Table 21.1). These microorganisms ferment glutamate to acetate only (Caloramator coolhaasii [Plugge et al. 2000] and Caloramator proteoclasticus [Tarlera and Stams 1999]), propionate only (Aminobacterium colombiense [Baena et al. 1998] and Gelria glutamica [Plugge et al. 2002]), or acetate plus propionate (A. hydrogenoformans [Stams and Hansen 1984; Meijer et al. 1999], T. acidaminovorans [Cheng et al. 1992; Baena et al. 1999b], and Aminomonas paucivorans [Baena et al. 1999a]), with $\mathrm{CO}_{2}$ as coproduct (\$ Table 21.1).

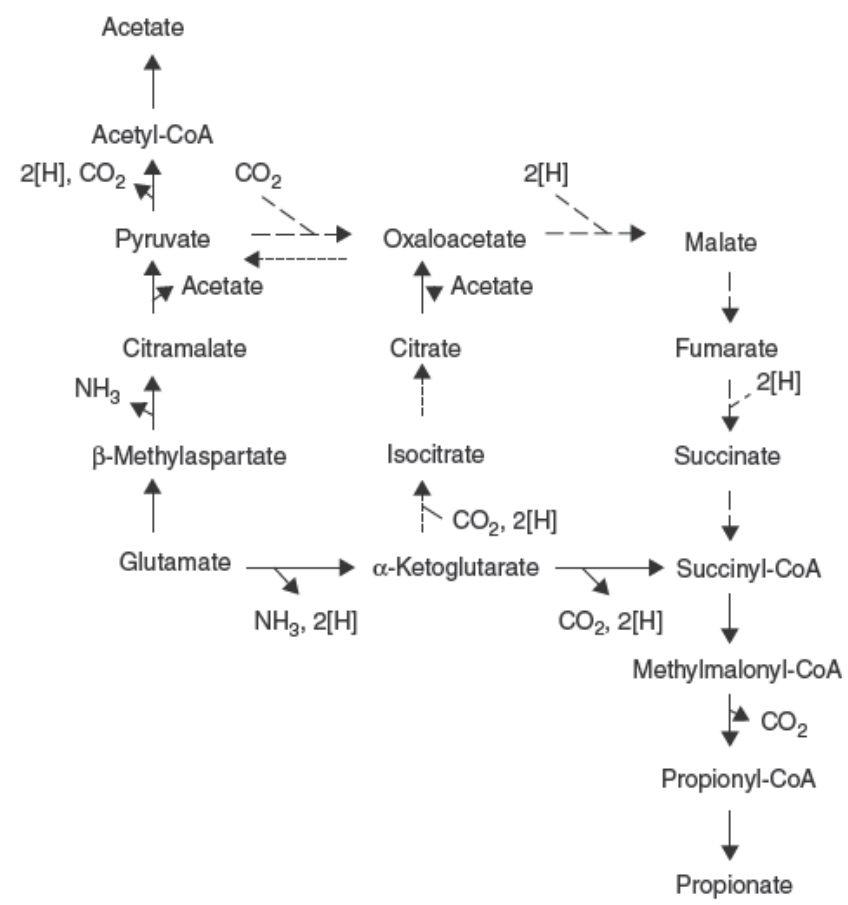

D Fig. 21.2

Pathways involved in the fermentation of glutamate to propionate and acetate in anaerobic bacteria. Thin solid line (left part): acetate formation by the commonly used

$\beta$-methylaspartate pathway. Thick solid line: oxidative formation of propionate as catalyzed by, e.g., Gelria glutamica. Dashed line: reductive formation of propionate as performed by Anaeromusa acidaminophila. Dotted line: acetate formation via enzymes of the reductive tricarboxylic acid (TCA) cycle as used by Acidaminobacter hydrogenoformans when cocultured with hydrogenotrophic methanogens

Acidaminobacter hydrogenoformans ferments glutamate to 2 acetate, $1 \mathrm{CO}_{2}, \mathrm{NH}_{3}$, and $1 \mathrm{H}_{2}$, or to 1 propionate, $2 \mathrm{CO}_{2}, \mathrm{NH}_{3}$, and $2 \mathrm{H}_{2}$ (๑ Table 21.1; ○ Fig. 21.2). In pure culture, A. hydrogenoformans can also form formate. However, in the presence of the hydrogen utilizing Methanobrevibacter arboriphilus, formate is not formed (Stams and Hansen 1984). The ratio at which acetate and propionate are formed depends on the hydrogen partial pressure (Stams and Hansen 1984). Propionate formation is favored at low hydrogen partial pressure, whereas at high hydrogen pressure, mainly acetate is formed. Enzyme measurements revealed that the strain when grown in pure culture uses the $\beta$ methylaspartate pathway for acetate for mation. However, if the bacterium is grown in coculture with a methanogen, both acetate and propionate appear to be formed via $\alpha$ ketoglutarate (Stams et al. 1998). Reductive carboxylation of $\alpha$ ketogluratate leads via isocitrate to citrate which is cleaved to acetate and pyruvate, and pyruvate is converted further to acetate. Propionate formation occurs via oxidative decarboxylation of $\alpha$ ketoglutarate to succinyl CoA, which is further converted to propionate. Apparently, a crucial step that determines the degra dation pathway is the oxidative deamination of glutamate to 
$\alpha$ ketoglutarate which is highly endergonic if coupled to hydrogen formation. Under standard conditions, this conversion is ener getically impossible $\left(\Delta \mathrm{G}_{0}{ }^{\prime}=+60 \mathrm{~kJ}\right.$ per mol). However, at a hydrogen partial pressure of $10^{-5}$ atm, the $\Delta \mathrm{G}_{0}{ }^{\prime}$ of this reaction would be $+30 \mathrm{~kJ}$ per mol, and if the intracellular $\mathrm{NH}^{4+}$ concen tration would be $10 \mathrm{mM}$ and the glutamate/ $\alpha$ ketoglutarate ratio about 500, the $\Delta \mathrm{G}^{\prime}$ of this reaction would become about zero. A similar shift in product formation was described for Aminomonas paucivorans (Baena et al. 1999a).

Thermanaerovibrio acidaminovorans also forms acetate and propionate as products. Unlike the mesophilic organisms, this thermophile forms propionate already in pure culture. This bacterium uses the $\beta$ methylaspartate pathway for acetate for mation both in pure culture and in coculture with a methanogen (Plugge et al. 2002). Some of the glutamate fermenting bacteria also are able to grow with histidine, forming similar products and shifts in product formation as with glutamate. Histidine is supposed to be degraded through glutamate as an intermediate (Gottschalk 1986).

\section{Stickland Reaction Versus Methanogenesis}

Some of the bacteria which can degrade amino acids syntrophically, including Clostridium sporogenes, Eubacterium acidaminophilum, Acidaminobacter hydrogenoformans, and Caloramator proteoclasticus, are able to perform a Stickland reaction. The environmental conditions under which the Stickland reaction is favored and conditions under which reduc ing equivalents are disposed of as molecular hydrogen remain to be determined. Energetically, the reductive conversion of glycine is more favorable than methanogenesis, homoacetogenesis, or sulfate reduction ( Table 21.2). It is likely that in environments rich in amino acids, the Stickland reaction will dominate, whereas in environments with low amino acid supply and high

- Table 21.2

Changes of Gibbs free energies under standard conditions in hydrogen-consuming reactions involved in interspecies hydrogen transfer

\begin{tabular}{|l|c|c|}
\hline & $\begin{array}{l}\Delta \mathrm{G}_{0}{ }^{\prime} \text { (kJ per } \\
\mathbf{m o l} \text { rct.) }\end{array}$ & $\begin{array}{l}\Delta \mathbf{G}_{\mathbf{0}}{ }^{\prime} \text { (kJ per } \\
\text { electron pair) }\end{array}$ \\
\hline $\begin{array}{l}4 \mathrm{H}_{2}+2 \mathrm{CO}_{2} \rightarrow \mathrm{CH}_{3} \mathrm{COO}^{-}+ \\
\mathrm{H}^{+}+2 \mathrm{H}_{2} \mathrm{O}\end{array}$ & 94.9 & 23.8 \\
\hline $4 \mathrm{H}_{2}+\mathrm{CO}_{2} \rightarrow \mathrm{CH}_{4}+2 \mathrm{H}_{2} \mathrm{O}$ & 131.0 & 32.7 \\
\hline $\mathrm{H}_{2}+\mathrm{S}^{0} \rightarrow \mathrm{H}_{2} \mathrm{~S}$ & 33.9 & 33.9 \\
\hline $\begin{array}{l}4 \mathrm{H}_{2}+\mathrm{SO}_{4}{ }^{2-}+\mathrm{H}^{+} \rightarrow \mathrm{HS}^{-}+ \\
4 \mathrm{H}_{2} \mathrm{O}\end{array}$ & 151.0 & 37.6 \\
\hline $\begin{array}{l}\mathrm{H}_{2} \mathrm{C}\left(\mathrm{NH}_{3}{ }^{+}\right) \mathrm{COO}^{-}+\mathrm{H}_{2} \rightarrow \\
\mathrm{CH}_{3} \mathrm{COO}^{-}+\mathrm{NH}_{4}{ }^{+}\end{array}$ & 78.0 & 78.0 \\
\hline $\begin{array}{l}\text { Fumarate } \\
\text { succinate }\end{array}$ & 86.0 & 86.0 \\
\hline
\end{tabular}

All calculations are based on published tables (see Thauer et al. 1977; Dimroth 1983). For $\mathrm{H}_{2} \mathrm{~S}$ and $\mathrm{CO}_{2}$, values for the gaseous state were used methanogenic activity, reducing equivalents may be preferen tially channeled to methanogenesis. Unfortunately, up to now, little information was available on such comparative ecological aspects.

During growth of a coculture of Caloramator proteoclasticus and Methanobacterium thermoautotrophicum Z245 in a medium with alanine plus glycine, about $60 \%$ of the reducing equivalents were channeled to methanogenesis when a dense culture of the methanogen was inoculated with $0.2 \%$ of a culture of C. proteoclasticus. However, if $1 \%$ inoculum was applied, all the reducing equivalents were used to reduce glycine.

\section{Syntrophic Degradation of Fermentation Intermediates}

\section{Syntrophic Ethanol Oxidation}

The case of Methanobacillus omelianskii is the classical example of interspecies hydrogen transfer. Both partners operate in an overall reaction process which becomes exergonic for the first partner only through maintenance of a low hydrogen partial pressure by the second partner. After description of the cooper ative nature of this process, the original S strain was lost, but other syntrophically ethanol oxidizing bacteria have been iso lated, such as Thermoanaerobium brockii (Ben Bassat et al. 1981) and various Pelobacter strains (Schink 1984, 1985a; Eichler and Schink 1986). Also certain ethanol oxidizing sulfate reducers such as Desulfovibrio vulgaris are able to oxidize ethanol in the absence of sulfate by hydrogen transfer to a hydrogen oxidizing methanogenic partner.

Unfortunately, the biochemistry of this syntrophic coopera tion has not been resolved yet. The total reaction

$$
2 \mathrm{CH}_{3} \mathrm{CH}_{2} \mathrm{OH}+\mathrm{CO}_{2} \rightarrow 2 \mathrm{CH}_{3} \mathrm{COO}+2 \mathrm{H}^{+}+\mathrm{CH}_{4}
$$

yields $-112 \mathrm{~kJ}$ per $2 \mathrm{~mol}$ ethanol under standard conditions. On the side of the ethanol oxidizer, e.g., the "S strain" of Methanobacillus omelianskii (Bryant et al. 1967) or other fermenting anaerobes with similar metabolic capacities such as Pelobacter acetylenicus (Schink 1985a), ethanol dehydrogenase, acetaldehyde ferredoxin oxidoreductase (acetyl CoA forming), phosphotransacetylase, and acetate kinase have been shown to be involved, forming one ATP per ethanol through substrate level phosphorylation. Since the methanogenic hydrogen oxi dizer requires at least one third of an ATP unit for growth ( $-20 \mathrm{~kJ}$ per reaction run, see above), only about $-45 \mathrm{~kJ}$ is available to the ethanol oxidizer per mol ethanol oxidized, which is too little energy to form one full ATP. It has to be postulated, therefore, that part of the energy bound in ATP has to be reinvested somewhere to push the overall reaction and balance the energy budget, but this reverse electron transport system has not yet been identified. In syntrophically ethanol oxidizing Desulfovibrio strains, the pathway leads from acetalde hyde directly to acetate, without a phosphorylation step, which explains why Desulfovibrio cannot grow in this syntrophic asso ciation (Kremer et al. 1988). 


\section{Syntrophic Butyrate Oxidation}

Similar cooperations have been described with syntrophic cul tures degrading fatty acids. An overview of the reactions cata lyzed is presented in $\mathbf{O}$ Table 21.3; a list of described strains of syntrophically fermenting bacteria follows in $\mathbf{0}$ Table 21.4. In general, degradation of fatty acids to acetate and hydrogen or, in the case of propionate, to acetate, hydrogen, and $\mathrm{CO}_{2}$ are reactions far more endergonic under standard conditions than ethanol oxidation. Consequently, for fatty acid degradation, the hydrogen partial pressure has to be decreased to substantially lower values $\left(<10^{-4}\right.$ bar $)$ than with ethanol $\left(<10^{-3}\right.$ bar $)$.

The energetic situation of the partner bacteria involved in butyrate conversion to methane and $\mathrm{CO}_{2}$ has been discussed in detail in earlier publications (Wallrabenstein and Schink 1994; Schink 1997). The overall reaction

$$
2 \mathrm{CH}_{3} \mathrm{CH}_{2} \mathrm{CH}_{2} \mathrm{COO}+2 \mathrm{H}^{+}+2 \mathrm{H}_{2} \mathrm{O} \rightarrow 5 \mathrm{CH}_{4}+3 \mathrm{CO}_{2}
$$

yields under standard conditions a $\Delta \mathrm{G}_{0}{ }^{\prime}$ of $-177 \mathrm{~kJ}$ per 2 mol of butyrate. With concentrations better comparable to those prevailing in a natural habitat, e.g., a freshwater sediment or

\section{- Table 21.3}

Changes of Gibbs free energies under standard conditions in hydrogen-releasing reactions during oxidation of fermentation intermediates

\begin{tabular}{|c|c|c|}
\hline & $\begin{array}{l}\mathrm{G}_{0}^{\prime} \text { (kJ per } \\
\mathrm{mol} \text { rct.) }\end{array}$ & $\begin{array}{l}\text { No. of } \\
\text { electron pairs }\end{array}$ \\
\hline \multicolumn{3}{|l|}{ Primary alcohols } \\
\hline $\begin{array}{l}\mathrm{CH}_{3} \mathrm{CH}_{2} \mathrm{OH}+\mathrm{H}_{2} \mathrm{O} \rightarrow \mathrm{CH}_{3} \mathrm{COO}^{-}+ \\
\mathrm{H}^{+}+2 \mathrm{H}_{2}\end{array}$ & +9.6 & 2 \\
\hline \multicolumn{3}{|l|}{ Fatty acids } \\
\hline $\begin{array}{l}\mathrm{CH}_{3} \mathrm{CH}_{2} \mathrm{CH}_{2} \mathrm{COO}^{-}+2 \mathrm{H}_{2} \mathrm{O} \rightarrow \\
2 \mathrm{CH}_{3} \mathrm{COO}^{-}+2 \mathrm{H}^{+}+2 \mathrm{H}_{2}\end{array}$ & +48.3 & 2 \\
\hline $\begin{array}{l}\mathrm{CH}_{3} \mathrm{CH}_{2} \mathrm{COO}^{-}+2 \mathrm{H}_{2} \mathrm{O} \rightarrow \\
\mathrm{CH}_{3} \mathrm{COO}^{-}+\mathrm{CO}_{2}+3 \mathrm{H}_{2}\end{array}$ & +76.0 & 3 \\
\hline $\begin{array}{l}\mathrm{CH}_{3} \mathrm{COO}^{-}+\mathrm{H}^{+}+2 \mathrm{H}_{2} \mathrm{O} \rightarrow \\
2 \mathrm{CO}_{2}+4 \mathrm{H}_{2}\end{array}$ & +94.9 & 4 \\
\hline $\begin{array}{l}\mathrm{CH}_{3} \mathrm{CH}\left(\mathrm{CH}_{3}\right) \mathrm{CH}_{2} \mathrm{COO}^{-}+\mathrm{CO}_{2}+ \\
2 \mathrm{H}_{2} \mathrm{O} \rightarrow 3 \mathrm{CH}_{3} \mathrm{COO}^{-}+2 \mathrm{H}^{+}+\mathrm{H}_{2}\end{array}$ & +25.2 & 1 \\
\hline \multicolumn{3}{|l|}{ Glycolic acid } \\
\hline $\begin{array}{l}\mathrm{CH}_{2} \mathrm{OHCOO}^{-}+\mathrm{H}^{+}+\mathrm{H}_{2} \mathrm{O} \rightarrow \\
2 \mathrm{CO}_{2}+3 \mathrm{H}_{2}\end{array}$ & +19.3 & 3 \\
\hline \multicolumn{3}{|l|}{ Aromatic compounds } \\
\hline $\begin{array}{l}\mathrm{C}_{6} \mathrm{H}_{5} \mathrm{COO}^{-}+6 \mathrm{H}_{2} \mathrm{O} \rightarrow 3 \mathrm{CH}_{3} \mathrm{COO}^{-}+ \\
2 \mathrm{H}^{+}+\mathrm{CO}_{2}+3 \mathrm{H}_{2}\end{array}$ & +49.5 & 3 \\
\hline $\begin{array}{l}\mathrm{C}_{6} \mathrm{H}_{5} \mathrm{OH}+5 \mathrm{H}_{2} \mathrm{O} \rightarrow 3 \mathrm{CH}_{3} \mathrm{COO}^{-}+ \\
3 \mathrm{H}^{+}+2 \mathrm{H}_{2}\end{array}$ & +10.2 & 2 \\
\hline \multicolumn{3}{|l|}{ Amino acids } \\
\hline $\begin{array}{l}\mathrm{CH}_{3} \mathrm{CH}\left(\mathrm{NH}_{3}{ }^{+}\right) \mathrm{COO}^{-}+2 \mathrm{H}_{2} \mathrm{O} \rightarrow \\
\mathrm{CH}_{3} \mathrm{COO}^{-}+\mathrm{NH}_{4}^{+}+\mathrm{CO}_{2}+2 \mathrm{H}_{2}\end{array}$ & +2.7 & 2 \\
\hline
\end{tabular}

All calculations are based on published tables (see Thauer et al. 1977; Dimroth 1983). For $\mathrm{H}_{2} \mathrm{~S}$ and $\mathrm{CO}_{2}$, values for the gaseous state were used a sewage sludge digestor (butyrate: $10 \mu \mathrm{M}, \mathrm{CH}_{4}$ : 0.7 bar, and $\mathrm{CO}_{2}: 0.3 \mathrm{bar}$ ), the free energy of this process changes to $-140 \mathrm{~kJ}$ per $2 \mathrm{~mol}$ of butyrate. Since the overall process is shared by seven partial reactions (two are involved in the butyrate oxidation, one in $\mathrm{CO}_{2}$ reduction to methane, and four in acetate cleavage), the free energy change is about $-20 \mathrm{~kJ}$ per mol for every partial reaction if the energy is shared by all reactions at equal rates. Measured partial pressures of hydrogen and acetate concentra tions in active sewage sludge and various sediments (Zehnder et al. 1982) are in a range of $10^{-4}$ to $10^{-5}$ bar and $10100 \mu \mathrm{M}$, respectively, which is in good agreement with the assumption of equal energy sharing in such a cooperative community. The corresponding energy yields of about $-20 \mathrm{~kJ}$ per mol reaction are confirmed by growth yield determinations with pure cultures of methanogens (Schönheit et al. 1980; Zehnder et al. 1982).

On the side of the syntrophically fermenting partner, 1 ATP is synthesized by substrate level phosphorylation through thiolytic acetoacetyl CoA cleavage (Wofford et al. 1986), but part of this energy has to be reinvested into an assumed reverse electron transport to allow proton reduction with electrons from the butyryl CoA dehydrogenase reaction at a hydrogen partial pressure of $10^{-4}$ to $10^{-5}$ bar (Thauer and Morris 1984). Exper imental evidence of a reverse electron transport system between the crotonyl CoA/butyryl CoA couple $\left(\mathrm{E}^{\circ \prime}=-125 \mathrm{mV}\right)$ and the $\mathrm{H}^{+} / \mathrm{H}_{2}$ couple has been provided with Syntrophomonas wolfei (Wallrabenstein and Schink 1994). In the meantime, several components of this electron transport system have been described in detail (Müller et al. 2009) on the basis of the sequenced genome of Syntrophomonas wolfei (McInerney et al. 2007). The present concept assumes that the menaquinone involved as electron carrier in this system translocates protons from the outside inward, thus pushing the endergonic reduction of protons with the electrons released in the butyryl CoA dehy drogenase reaction. If two protons are transferred this way, one third of the ATP synthesized by substrate level phosphorylation (equivalent to $-20 \mathrm{~kJ}$ per mol) would remain for growth and maintenance of the fatty acid oxidizing bacterium, in accor dance with the above assumptions.

The energetic situation of a binary mixed culture degrading butyrate to acetate and methane is considerably more difficult:

$$
\begin{aligned}
& 2 \mathrm{CH}_{3} \mathrm{CH}_{2} \mathrm{CH}_{2} \mathrm{COO}^{-}+\mathrm{CO}_{2}+2 \mathrm{H}_{2} \mathrm{O} \rightarrow 4 \mathrm{CH}_{3} \mathrm{COO}^{-}+2 \mathrm{H}^{+}+\mathrm{CH}_{4} \\
& \Delta \mathrm{G}_{0}{ }^{\prime} \quad 35 \mathrm{~kJ} \text { per } 2 \mathrm{~mol} \text { of butyrate }
\end{aligned}
$$

This overall reaction has to feed two organisms in three partial reactions, so each step has only $-12 \mathrm{~kJ}$ available under standard conditions, and the total changes to $-46 \mathrm{~kJ}$ at butyrate and acetate concentrations in the range of $10 \mathrm{mM}$ as used in laboratory cultures. Under these conditions, the energetic situation for the partners gets tough $(-15 \mathrm{~kJ}$ per mol reaction), especially at the end of the substrate conversion process. Very slow, often nonexponential growth and substrate turnover as usually observed with such binary mixed cultures (Dwyer et al. 1988) indicates that the energy supply is insufficient. We have often observed, as did other authors, that accumulating acetate $(>10 \mathrm{mM})$ inhibits butyrate degradation in such cultures substantially. 
- Table 21.4

Pure or defined mixed cultures of bacteria catalyzing syntrophic substrate oxidations via interspecies hydrogen transfer

\section{Isolate}

Substrate range

\begin{tabular}{|l|l|l} 
Gram type & Phylogenetic position & References
\end{tabular}

(a) Oxidation of primary alcohols

\begin{tabular}{|l|l|l|l|l}
\hline S-strain & Ethanol & & Unknown & Bryant et al. (1967) \\
\hline Desulfovibrio vulgaris & Ethanol + sulfate & & $\delta$-Proteobacteria & Bryant et al. (1977) \\
\hline $\begin{array}{l}\text { Thermoanaerobacter } \\
\text { brockii }\end{array}$ & Ethanol, sugars, etc. & + & Low G + C Gram positives & Ben-Bassat et al. (1981) \\
\hline Pelobacter venetianus & Ethanol, propanol & & $\delta$-Proteobacteria & Schink and Stieb (1983) \\
\hline Pelobacter acetylenicus & Ethanol, acetylene & & $\delta$-Proteobacteria & Schink (1985a) \\
\hline Pelobacter carbinolicus & Ethanol, 2,3-butanediol & & $\delta$-Proteobacteria & Schink (1984) \\
\hline
\end{tabular}

(b) Oxidation of butyrate and higher homologues

\begin{tabular}{|l|l|l|l|l|}
\hline $\begin{array}{l}\text { Syntrophomonas } \\
\text { wolfei }\end{array}$ & $\mathrm{C}_{4} \mathrm{C}_{8}$ & & Low G + C Gram positives & Mclnerney et al. (1979, 1981) \\
\hline $\begin{array}{l}\text { Syntrophomonas } \\
\text { sapovorans }\end{array}$ & $\mathrm{C}_{4} \mathrm{C}_{18}$ & & Low G + C Gram positives & Roy et al. (1986) \\
\hline $\begin{array}{l}\text { Syntrophospora } \\
\text { bryantii }\end{array}$ & $\mathrm{C}_{4} \mathrm{C}_{11}$, 2-methyl valerate & + & Low G + C Gram positives & $\begin{array}{l}\text { Stieb and Schink (1985); } \\
\text { Zhao et al. (1989) }\end{array}$ \\
\hline $\begin{array}{l}\text { Thermosyntropha } \\
\text { lipolytica }\end{array}$ & $\mathrm{C}_{4} \mathrm{C}_{18}$, crotonate, and betaine & + & Low G + C Gram positives & Svetlitshnyi et al. (1996) \\
\hline $\begin{array}{l}\text { Syntrophothermus } \\
\text { lipocalidus }\end{array}$ & $\mathrm{C}_{4} \mathrm{C}_{10}$, isobutyrate, and crotonate & + & Low G + C Gram positives & Sekiguchi et al. (2000) \\
\hline
\end{tabular}

(c) Oxidation of propionate

\begin{tabular}{|l|l|l|l|l|}
\hline $\begin{array}{l}\text { Syntrophobacter } \\
\text { wolinii }\end{array}$ & Propionate & & $\delta$-Proteobacteria & Boone and Bryant (1980) \\
\hline $\begin{array}{l}\text { Syntrophobacter } \\
\text { pfennigii }\end{array}$ & Pyruvate & & $\delta$-Proteobacteria & Wallrabenstein et al. (1995a) \\
\hline $\begin{array}{l}\text { Syntrophobacter } \\
\text { fumaroxidans }\end{array}$ & Propionate + fumarate & & $\delta$-Proteobacteria & Harmsen et al. (1998) \\
\hline Smithella propionica & Propionate & & $\delta$-Proteobacteria & Liu et al. (1999) \\
\hline
\end{tabular}

(d) Oxidation of acetate

\begin{tabular}{|l|l|l|l|l|}
\hline $\begin{array}{l}\text { Thermoacetogenium } \\
\text { phaeum }\end{array}$ & $\begin{array}{l}\text { Acetate, pyruvate, glycine, cysteine, } \\
\text { formate, and } \mathrm{H}_{2} / \mathrm{CO}_{2}\end{array}$ & + & Low G + C Gram positives & Hattori et al. (2000) \\
\hline Clostridium ultunense & Acetate, formate, and cysteine & + & Low G + C Gram positives & Schnürer et al. (1996) \\
\hline (e) & &
\end{tabular}

(e) Oxidation of isovalerate

\begin{tabular}{|l|l|l|l|l}
\hline Strain Gralva1 & Isovalerate only & + & Unknown & Stieb and Schink (1986) \\
\hline
\end{tabular}

(f) Oxidation of glycolate

\begin{tabular}{|l|l|l|l|l|}
\hline $\begin{array}{l}\text { Syntrophobotulus } \\
\text { glycolicus }\end{array}$ & Glycolate and glyoxylate & + & Low G + C Gram positives & Friedrich et al. (1991, 1996) \\
\hline
\end{tabular}

(g) Oxidation of aromatic compounds

\begin{tabular}{|l|l|l|l|l|}
\hline Syntrophus buswellii & Benzoate and crotonate & & $\delta$-Proteobacteria & Mountfort and Bryant (1982) \\
\hline Syntrophus gentianae & Benzoate, gentisate, and hydroquinone & & $\delta$-Proteobacteria & Wallrabenstein et al. (1995b) \\
\hline $\begin{array}{l}\text { Syntrophus } \\
\text { aciditrophicus }\end{array}$ & Benzoate and crotonate & & $\delta$-Proteobacteria & Jackson et al. (1999) \\
\hline
\end{tabular}

The energetic difference between the ternary mixed culture and an artificial binary mixed culture demonstrates that the acetate cleaving methanogens fill an important function in removal of acetate and, with this, "pull" the butyrate oxidation reaction. The above calculations also explain why addition of an acetate cleaving methanogen to a defined binary mixed culture enhances growth and substrate turnover considerably (Ahring and Westermann 1988; Beaty and McInerney 1989).

Syntrophic oxidation of long chain fatty acids from lipid hydrolysis probably proceeds via $\beta$ oxidation with concomitant 
release of electrons as hydrogen via reverse electron transport, analogous to the process described above for butyrate oxidation. Long chain dicarboxylic acids are degraded stepwise by $\beta$ oxidation, analogous to fatty acids, and decarboxylation occurs at the C5 or C4 state (glutarate or succinate; Matthies and Schink 1993).

\section{Syntrophic Propionate Oxidation}

For syntrophic propionate oxidation according to the equation

$$
\begin{gathered}
4 \mathrm{CH}_{3} \mathrm{CH}_{2} \mathrm{COO}+4 \mathrm{H}^{+}+2 \mathrm{H}_{2} \mathrm{O} \rightarrow 7 \mathrm{CH}_{4}+5 \mathrm{CO}_{2} \\
\Delta \mathrm{G}_{0}{ }^{\prime}=-249 \mathrm{~kJ} \text { per } 4 \mathrm{~mol} \text { of propionate }
\end{gathered}
$$

a metabolic flow scheme can be drawn, leaving a free energy change in the range of -22 to $-23 \mathrm{~kJ}$ per mol reaction (11 partial reactions) to all partners involved (Stams et al. 1989; Schink 1991). Studies in defined mixed cultures and in undefined com munities in rice field soil have basically confirmed this assump tion, although the amount of energy available to the propionate oxidizer may be sometimes substantially lower (Scholten and Conrad 2000; Fey and Conrad 2000).

The ability to grow on propionate in syntrophic association with methanogenic archaea is found in two phylogenetic groups of bacteria. Boone and Bryant (1980) described Syntrophobacter wolinii. Since then, several other mesophilic and thermophilic bacteria that grow in syntrophy with methanogens have been described as reviewed by McInerney et al. (2008) These include Gram negative bacteria (Syntrophobacter and Smithella) and Gram positive bacteria (Pelotomaculum and Desulfotomaculum). Phylogenetically, both groups are related to sulfate reducing bacteria and some indeed grow by coupling propionate oxidation to sulfate reduction (Harmsen et al. 1993, 1995; Wallrabenstein et al. 1994, 1995a; Chen et al. 2005). Most syntrophically propionate degrading bacteria are able to grow in pure culture by fermentation of fumarate or pyruvate. The exceptions are Pelotomaculum schinkii (de Bok et al. 2005) and Pelotomaculum propionicicum (Imachi et al. 2007), which seem to be true propionate degrading syntrophs.

Two pathways for propionate metabolism are known, the methylmalonyl CoA pathway and a dismutation pathway. In the latter pathway, two propionate molecules are converted to ace tate and butyrate, the butyrate being degraded to acetate and hydrogen as described above. Thus far, this pathway is only found in Smithella propionica (Liu et al. 1999; de Bok et al. 2001). The methylmalonyl CoA pathway is found in the other syntrophic propionate oxidizing bacteria (McInerney et al. 2008). This pathway is basically a reversal of fermentative pro pionate formation, including methylmalonyl CoA, succinate, malate, pyruvate, and acetyl CoA as intermediates (Koch et al. 1983; Schink 1985b, 1991; Houwen et al. 1987, 1990; Kosaka et al. 2006). The initial substrate activation is accomplished by CoA transfer from acetyl CoA (Houwen et al. 1990; Plugge et al. 1993) or succinyl CoA. Of the redox reactions involved, succi nate oxidation and malate oxidation are the most difficult ones to couple to proton reduction: Hydrogen partial pressures of $10^{-15}$ or $10^{-8}$ bar would be required, respectively, which are far lower concentrations than a methanogen can maintain. The enzymes and electron transfer components involved in propio nate oxidation were initially studied with Syntrophobacter wolinii (Houwen et al. 1990; Plugge et al. 1993) and Syntrophobacter pfennigii (Wallrabenstein et al. 1995b). Genome based studies have recently been done with Syntrophobacter fumaroxidans (Müller et al. 2010; Worm et al. 2011) and the thermophilic Pelotomaculum thermopropionicum (Kosaka et al. 2006, 2008).

Studies with Syntrophobacter fumaroxidans have shown that not only hydrogen but also formate could contribute to inter species electron transport; syntrophic propionate oxidation was possible only in cooperation with formate and hydrogen oxidizing methanogens and not with Methanobrevibacter strains that are unable to use formate (Dong et al. 1994). This view was further supported by enzyme measurements; cells grown syntrophically with propionate contained tenfold higher for mate dehydrogenase activity in comparison with cells grown in pure culture with fumarate; the hydrogenase activity was unchanged (de Bok et al. 2002). The complexity of interspecies electron transfer became clear in a recent study in which six different hydrogenases, four formate dehydrogenases, and two formate hydrogen lyases were identified in S. fumaroxidans, and five formate dehydrogenases and three hydrogenases in the methanogenic partner Methanospirillum hungatei (Worm et al. 2011). All these enzymes are involved, but the relative impor tance of each enzyme is not yet clear.

In syntrophic propionate metabolism, menaquinone oxidation is linked to a membrane bound hydrogenase or for mate dehydrogenase. Genome and biochemical analysis of S. fumaroxidans revealed the presence of a membrane integrated succinate dehydrogenase gene cluster containing menaquinone (Sfum 1998, 1999 and 2000) and several periplasmic and cytoplasmic hydrogenases and formate dehydrogenases (Müller et al. 2010; Worm et al. 2011). A requirement of 2/3 ATP for reversed electron transport was determined to push the endergonic succinate oxidation. A similar and phylogenetically related succinate dehydrogenase gene cluster was found in P. thermopropionicum (Kosaka et al. 2006, 2008). This indicates that succinate oxidation to fumarate requires a proton gradient over the membrane and the investment of ATP to form hydrogen or formate at the outside of the cytoplasmic membrane.

Smithella propionica (Liu et al. 1999) uses a different pathway to convert propionate. The labeling patterns of products formed from specifically labeled propionate indicate that propionate degradation by this bacterium proceeds through dimerization of propionate to a six carbon intermediate that is subsequently cleaved to an acetyl and a butyryl moiety, with partial further oxidation (de Bok et al. 2001). This new pathway could also explain the results of labeling experiments with an enrichment culture which were first interpreted as indicative of a reductive carboxylation of propionate to a butyryl residue (Tholozan et al. 1988, 1990). 


\section{Syntrophic Acetate Oxidation}

A special case is the syntrophic conversion of acetate to $2 \mathrm{CO}_{2}$ and $4 \mathrm{H}_{2}$ which was described first for a moderately thermophilic $\left(58^{\circ} \mathrm{C}\right)$ bacterium, strain AOR (Zinder and Koch 1984). This syntrophic acetate oxidizer could be grown in pure culture like a homoacetogen by hydrogen dependent reduction of $\mathrm{CO}_{2}$ to acetate, thus reversing syntrophic acetate oxidation (Lee and Zinder 1988b, c). Biochemical studies revealed that it uses the carbon monoxide dehydrogenase pathway ("Wood Ljungdahl pathway"), as do other homoacetogens (Lee and Zinder 1988a). The small energy span available in acetate conversion to meth ane and $\mathrm{CO}_{2}$ is hardly sufficient to feed two bacteria:

$$
\begin{aligned}
& \mathrm{CH}_{3} \mathrm{COO}+\mathrm{H}^{+} \rightarrow \mathrm{CH}_{4}+\mathrm{CO}_{2} \\
& \begin{aligned}
\Delta \mathrm{G}_{0}{ }^{\prime}= & -36 \mathrm{~kJ} \text { per mol } \\
= & -8 \mathrm{~kJ} \text { per partial reaction }\left(\text { at } 25^{\circ} \mathrm{C}\right)
\end{aligned}
\end{aligned}
$$

The free energy change is slightly higher at $58^{\circ} \mathrm{C}(-42 \mathrm{~kJ}$ per $\mathrm{mol})$ than under standard conditions $\left(25^{\circ} \mathrm{C}\right)$. However, a syntrophic acetate oxidizing culture has been described as well which operates at $35^{\circ} \mathrm{C}$ (Schnürer et al. 1994, 1996) and thus proves that this free energy change $\left(-38^{\circ} \mathrm{C}\right)$ is sufficient for acetate degradation and (very slow) growth at this temperature. Another interesting feature of this type of metabolism is that these bacteria can run acetate formation and acetate degradation, in both direc tions, with probably the same biochemical reaction apparatus, just depending on the prevailing concentrations of substrates and products, and even can synthesize ATP both ways. This example shows how close to the thermodynamic equilibrium the energy metabolism of an anaerobic bacterium can operate.

The higher energy yield at elevated temperature may explain why at $35^{\circ} \mathrm{C}$ and lower this reaction is typically carried out by one single bacterium, e.g., Methanosarcina barkeri or Methanosaeta soehngenii, and why cooperations of syntrophic associations of the above mentioned type are found nearly exclusively at ele vated temperatures. Nonetheless, acetate conversion to methane at higher temperatures can as well be catalyzed by a single aceticlastic methanogen, e.g., Methanosarcina thermophila. Syntrophic acetate oxidation at lower temperatures is found only if further stress factors such as high ammonium concen trations inhibit aceticlastic methanogens (Schnürer et al. 1994).

Unfortunately, strain AOR was lost only few years after its description. Another thermophilic strain with similar proper ties, Thermoacetogenium phaeum, was isolated in Japan (Hattori et al. 2000) and was found to use the CO dehydrogenase pathway (the Wood Ljungdahl pathway) for acetate oxidation, too (Hattori et al. 2005), and the same is true for the mesophilic acetate oxidizing Clostridium ultunense (Schnürer et al. 1997). However, we do not know yet to what extent and in which steps energy is conserved by these bacteria: either in the acetate syn thesis or the acetate oxidation reaction chain.

Syntrophic acetate oxidation was observed also in a coculture of the iron reducing bacterium Geobacter sulfurreducens together with the nitrate reducing anaerobe Wolinella succinogenes (Cord Ruwisch et al. 1998). In this coculture, the hydrogen partial pressures were far below the levels observed in the cultures mentioned above. We found out later that the cysteine added to the cultures as reducing agent actually mediates interspecies electron transfer in this artificially composed syntrophic coculture through a cysteine/cystine cycle (Kaden et al. 2002), thus adding another means of electron transfer to our concepts of syntrophic cooperations.

\section{Syntrophic Glycolate Oxidation}

Glycolate is not a fermentation intermediate but an important excretion product of algal cells. It is syntrophically oxidized by homoacetogenic and methanogenic cocultures to two mole cules of $\mathrm{CO}_{2}$, and hydrogen is the electron carrier between the fermenting bacterium (Syntrophobotulus glycolicus) and a hydrogen oxidizing partner bacterium (Friedrich et al. 1991, 1996). The primary fermentation is an endergonic process under standard conditions ( $(7$ Table 21.3) and needs coupling to, e.g., a methanogenic partner. The degradation pathway includes oxidation of glycolate to glyoxylate, condensation of glyoxylate with acetyl CoA to form malyl CoA, ATP formation in a malyl CoA synthetase reaction, malate oxidation and decarboxylation by the malic enzyme, and oxidative decarboxylation of pyruvate to acetyl CoA through pyruvate synthase, thus closing the chain for a new reaction cycle (Friedrich et al. 1991). In this cycle, the oxidation of glycolate to glyoxylate is the critical oxidation step $\left(\mathrm{E}^{\circ \prime}=-92 \mathrm{mV}\right)$ which, if coupled to proton reduction, requires a reverse electron transport which has to be fueled by partial hydrolysis of the ATP formed in substrate level phosphoryla tion. Proof of proton gradient dependent hydrogen release was provided in experiments with membrane vesicles: Such vesicles converted glycolate stoichiometrically to glyoxylate and hydro gen in the presence of ATP. This hydrogen formation was abolished entirely by addition of CCCP and other protonophores, as well as by DCCD. Monensin and other sodium ionophores had no specific effect (Friedrich and Schink 1993). The process is even reversible: Membrane vesicles incu bated in the presence of glyoxylate and hydrogen catalyzed a substrate dependent net synthesis of ATP from ADP and $\mathrm{P}_{\mathrm{i}}$. The ratio of hydrogen dependent glyoxylate reduction over ATP formation in isolated membrane vesicle preparations (0.2 $0.5 \mathrm{~mol}$ per mol; Friedrich and Schink 1995) indicates that probably two thirds of an ATP unit can be formed this way per reaction run. Thus, at least with this system, we have rather reliable data on the reaction stoichiometry.

\section{Syntrophic Oxidation of Aromatic Compounds}

So far, defined syntrophic cocultures for methanogenic degra dation of aromatic substrates exist only for benzoate, gentisate, and hydroquinone ( $($ Table 21.3). The biochemistry of anaerobic degradation of aromatic compounds has been studied in most detail so far with benzoate, and a degradation pathway has been elaborated in the last years mainly with phototrophic and 
nitrate reducing bacteria (for reviews of this subject, see Fuchs et al. 1994; Heider and Fuchs 1997; Schink et al. 2000). The basic concept is an initial activation to benzoyl CoA by an acyl CoA synthetase reaction requiring two ATP equivalents, followed by partial ring saturation and subsequent ring opening by a mecha nism analogous to $\beta$ oxidation of fatty acids. The resulting $\mathrm{C}_{7}$ dicarboxylic acid undergoes further $\beta$ oxidation to form three acetate residues and one $\mathrm{CO}_{2}$.

The reductive dearomatization of benzoyl CoA in nitrate reducers requires two ATP equivalents and leads to cyclohexa 2,6 diene carboxyl CoA which undergoes further hydration and oxidation (Heider and Fuchs 1997). This makes the initial steps in the total process rather ATP consuming (four ATP equivalents consumed before ring cleavage). Nitrate reducers will gain these ATP investments back during subsequent oxidation of the acetyl residues.

Syntrophically benzoate oxidizing bacteria (Auburger and Winter 1992; Schöcke and Schink 1997; Elshahed et al. 2001) activate benzoate through a benzoyl CoA ligase reaction, too, which consumes two ATP units and forms pyrophosphate as side product. Part of the energy invested can be regained through a membrane bound, proton translocating pyrophosphatase (Schöcke and Schink 1998), and another frac tion of an ATP can be conserved by the action of a membrane bound, sodium ion translocating glutaconyl CoA decarboxylase which stores the energy of the $C_{5}$ dicarboxylic acid decarboxyl ation to crotonate in a transmembrane sodium ion gradient (Schöcke and Schink 1999).

An alternative reaction for benzoyl CoA reduction was described first in Geobacter metallireducens and appears to be used also in sulfate reducing and syntrophically fermenting bacteria (Kung et al. 2009, 2010; Löffler et al. 2011). This enzyme (class II benzoyl CoA reductase) does not require direct invest ment of ATP in the reduction but derives the necessary energy for the reduction step from a "bifurcation" reaction (Herrmann et al. 2008) in which the reduction of benzoyl CoA with reduced ferredoxin is coupled with simultaneous electron transfer from ferredoxin to NAD. The energy gap has to be filled by ion translocation dependent electron transfer from $\mathrm{NADH}$ to ferre doxin, e.g., through an Rnf transport system.

Although the energetic situation of syntrophic benzoate oxi dizers in methanogenic cocultures is substantially better than that of butyrate oxidizers, it appears that these bacteria depend on efficient acetate removal as well. Benzoate was nearly completely converted to acetate, methane, and $\mathrm{CO}_{2}$ in binary mixed cultures with Methanospirillum hungatei as hydrogen scavenger. Remnant benzoate concentrations at apparent equilibrium (in the range of $2070 \mu \mathrm{M}$ ) increased in the presence of added acetate or propio nate and decreased in the presence of a more efficient hydrogen consumer, e.g., a sulfate reducing partner. The corresponding hydrogen concentrations measured in such cultures were in the range of $0.5-5 \times 10^{-5}$ bar, leaving a total $\Delta \mathrm{G}$ of -30 to $-45 \mathrm{~kJ}$ per mol reaction for the benzoate degrader. Similar results were obtained during studies on the kinetics of benzoate degradation with Syntrophus aciditrophicus in the presence of a sulfate reducing partner bacterium (Warikoo et al. 1996).

\section{Syntrophic Oxidation of Branched-Chain Fatty Acids}

Branched chain fatty acids are formed during fermentative deg radation of the corresponding amino acids by oxidative deam ination and decarboxylation, or reductive deamination (see above). The further degradation is not difficult with 2 methyl butyrate (neovalerate) because it can be $\beta$ oxidized, analogous to the degradation of butyrate to acetate and propionate by, e.g., Syntrophospora bryantii (Stieb and Schink 1985). Methanogenic degradation of isobutyrate proceeds via isomerization to buty rate and further $\beta$ oxidation (Stieb and Schink 1989); the isobutyrate/butyrate isomerization has been described in a defined culture as a coenzyme $B_{12}$ dependent rearrangement of the carbon skeleton (Matthies and Schink 1992). A similar isomerization may also occur as a side reaction with valerate, leading to formation of 2 methyl butyrate (Wu et al. 1994). Whether a similar isomerization occurs also during isobutyrate degradation by the thermophilic Syntrophothermus lipocalidus (Sekiguchi et al. 2000) still remains to be examined.

So far, only one defined culture has been described as capable of fermentative degradation of 3 methyl butyrate (isovalerate; Stieb and Schink 1986), and this culture specializes in degrada tion of this substrate, converting it with $\mathrm{CO}_{2}$ as cosubstrate to three molecules of acetate and one molecule of hydrogen († Tables 21.3 and $(21.4)$. The pathway is rather complicated and involves a carboxylation, a dehydrogenation of a saturated fatty acid residue, and one substrate level phosphorylation step (Stieb and Schink 1986). The whole conversion is endergonic under standard conditions and depends on syntrophic hydrogen removal. Since three acetate residues are released per substrate molecule oxidized, acetate should have a far more pronounced influence on the total energetics. Details of the energetics of metabolism of this bacterium have been discussed earlier (Schink 1991).

\section{Fermentation of Acetone}

A special situation is the fermentative conversion of acetone to methane and $\mathrm{CO}_{2}$, which is catalyzed by syntrophically cooperating bacteria as well. In this case, acetate is the only intermediate between both partners, as illustrated by the follow ing equations:

$$
\begin{aligned}
& \mathrm{CH}_{3} \mathrm{COCH}_{3}+\mathrm{CO}_{2}+\mathrm{H}_{2} \mathrm{O} \rightarrow 2 \mathrm{CH}_{3} \mathrm{COO}+2 \mathrm{H}^{+} \\
& \Delta \mathrm{G}_{0}{ }^{\prime}=-25.8 \mathrm{~kJ} \text { per mol } \\
& 2 \mathrm{CH}_{3} \mathrm{COO}+2 \mathrm{H}^{+} \rightarrow 2 \mathrm{CH}_{4}+2 \mathrm{CO}_{2} \\
& \Delta \mathrm{G}_{0}{ }^{\prime}=-71.8 \mathrm{~kJ} \text { per mol } \\
& \mathrm{CH}_{3} \mathrm{COCH}_{3}+\mathrm{H}_{2} \mathrm{O} \rightarrow 2 \mathrm{CH}_{4}+\mathrm{CO}_{2} \\
& \Delta \mathrm{G}_{0}{ }^{\prime}=-97.6 \mathrm{~kJ} \text { per mol }
\end{aligned}
$$

Although in this case all partial reactions are exergonic under standard conditions, the primary fermenting bacterium depends on the methanogenic partner, and acetone degradation in the mixed culture is substantially impaired in the presence of 
acetylene as an inhibitor of methanogens (Platen and Schink 1987). Experiments with the primary acetone fermenting bac terium in dialysis cultures revealed that acetate accumulation at concentrations higher than $10 \mathrm{mM}$ inhibited growth and ace tone degradation (Platen et al. 1994). Under these conditions, the free energy available to the acetone fermenter is still in the range of $-40 \mathrm{~kJ}$ per mol. Since acetone metabolism by these bacteria starts with an endergonic carboxylation reaction, this might be the amount of energy that they need to invest into this primary substrate activation reaction, perhaps through a membrane associated enzyme system (Dimroth 1987). Unfor tunately, the acetone fermenting bacterium has not been obtained in pure culture yet, and hence detailed studies on its biochemistry and energetics could not be performed yet.

\section{Interspecies Metabolite Transfer}

Although hydrogen due to its small size and fast diffusion appears to be an ideal carrier for electrons between bacteria of different metabolic types, formate also can act in a similar man ner. A possible alternative involvement of formate in such elec tron transfer processes had been considered from the very beginning (Bryant et al. 1967; McInerney and Wofford 1992) because the original partner bacteria used could oxidize both hydrogen and formate. The standard redox potential of the $\mathrm{CO}_{2} /$ formate couple is nearly identical with that of $\mathrm{H}^{+} / \mathrm{H}_{2}$ at $\mathrm{pH} 7.0$ $(-420$ vs. $-414 \mathrm{mV})$, and hence the energetic problems are the same with both. Because both electron carrier systems couple inside the cell with similar, if not the same, electron transfer components, e.g., ferredoxins, most bacteria involved in inter species electron transfer exchange hydrogen against formate and vice versa (e.g., Wu et al. 1993; Bleicher and Winter 1994). This renders a differentiation between both electron transfer systems rather difficult, and in many cases, both carriers may even be used simultaneously (Schink 1991). Thus, a formate/CO 2 shut tle could replace hydrogen transfer, and this idea has been brought up again on the basis of experiments with undefined floc cultures from methanogenic fermenters (Thiele and Zeikus 1988) and with pure cultures (Thiele and Zeikus 1988; Zindel et al. 1988), as well as on the basis of calculations of diffusion kinetics (Boone et al. 1989a, b). Biochemical and genomic infor mation supports the combined occurrence of hydrogen and formate transfer (Müller et al. 2010). Even electron transfer via conductive nanowires has been proposed in cocultures of P. thermopropionicum (Gorby et al. 2006).

Exclusive action of hydrogen as electron carrier has been proven so far only for the butyrate oxidizing coculture Syntrophomonas wolfei (Wofford et al. 1986), the glycolate oxidizing Syntrophobotulus glycolicus (Friedrich and Schink 1993), and the thermophilic, syntrophically acetate oxidizing strain AOR (Lee and Zinder 1988a, b, c); all these strains exhibit in coculture high hydrogenase and very little formate dehydro genase activity. Syntrophic oxidation of propionate by Syntrophobacter fumaroxidans or of butyrate by Syntrophospora bryantii requires partner bacteria that are able to use both hydrogen and formate, indicating that both carriers are involved in interspecies electron transfer (Dörner 1992; Dong et al. 1994a, b; Dong and Stams 1995a, b). Nonetheless, hydrogenase activities in these cultures exceeded formate dehydrogenase activ ities substantially indicating that hydrogen played a dominant role as well. Similar conclusions were drawn from hydrogen and formate transfer experiments with thermophilic granular sludge preparations and different partner bacteria (Schnürer et al. 1994). In isobutyrate degrading cocultures, formate appeared to play a role besides hydrogen as an electron carrier (Wu et al. 1996). On the basis of calculations of diffusion kinetics (Boone et al. $1989 \mathrm{a}, \mathrm{b})$, one can speculate that formate/ $\mathrm{CO}_{2}$ would be the preferred electron transfer system in suspended cultures of sin gle cells where the carrier molecule has to diffuse over long distances through an aqueous phase, whereas hydrogen would be more efficient in densely packed aggregates which dominate in anaerobic digestors and probably also in sediments.

A key problem in an assessment of the relative importance of formate as electron shuttle is a reliable measurement of formate at low concentrations: At 0.3 bar $\mathrm{CO}_{2}$ as typical of, e.g., sewage sludge or sediments, a hydrogen partial pressure of $10^{-4}$ to $10^{-5}$ bar (as required for the redox reactions discussed) is equivalent to formate concentrations of about $110 \mu \mathrm{M}$ (Schink 1994). Whereas hydrogen partial pressures can today be mea sured reliably down to $10^{-7}$ bar with mercury oxide based detectors, there is hardly an efficient method available which allows measurement of formate in concentrations of few micro molar and less. Moreover, most indications of formate forma tion were obtained in the presence of inhibitors that caused accumulation of measurable amounts of formate, but it remains doubtful whether such experiments describe adequately the electron flow in the undisturbed system.

Interestingly, besides the fact that methanogenic conversion can be driven by interspecies hydrogen and formate transfer, formate maybe a substrate for syntrophic growth as was demonstrated for mesophilic and thermophilic cocultures of anaerobic bacteria and hydrogen consuming archaea (Dolfing et al. 2008).

Beyond hydrogen and formate, acetate is also excreted by syntrophically fermenting bacteria and is further metabolized by methanogens. The model used above shows that also acetate removal can have a profound influence on the total energetics of syntrophic degradation of fatty acids or benzoate. Its impor tance may be even higher with, e.g., isovalerate degradation, since three molecules of acetate and only one hydrogen molecule are formed ( $($ Table 21.3). Indeed, inhibition by acetate accu mulations or by addition of acetate has been reported for syntrophic degradation of fatty acids and for benzoate (Ahring and Westermann 1988; Fukuzaki et al. 1990; van Lier et al. 1993; Warikoo et al. 1996; Schöcke and Schink 1997).

In the acetate oxidizing coculture of Geobacter sulfurreducens with Wolinella succinogenes mentioned above, we observed that a cysteine/cystine cycle acts as electron carrier between both partners (Kaden et al. 2002). The use of this carrier system of higher redox potential $\left(\mathrm{E}^{\circ \prime}=-270 \mathrm{mV}\right)$ than the hydrogen or formate system makes sense in the coupling to the 
comparably positive electron acceptor used by this coculture. Perhaps similar sulfur based carriers are active also in other syntrophic associations which exhibit fast electron transfer to an acceptor system of comparably high redox potential (Daniel et al. 1999; Meckenstock 1999). In the natural environment, also exogenous electron carriers such as humic substances may play a role as interspecies electron carriers, as suggested for electron transfer from iron reducing bacteria to insoluble iron minerals (Lovley et al. 1996). Cervantes et al. (2000) observed recently that the oxidation of phenolic compounds in methanogenic sewage sludge can be coupled to the reduction of the humic compound analogue anthraquinone 2,6 disulfonate, indicating that this acceptor could perhaps be reduced also by syntrophic phenol oxidizers.

\section{Anaerobic Methane Oxidation}

Anaerobic, sulfate dependent methane oxidation is an impor tant reaction in anoxic marine sediments, as documented on the basis of measurements of sulfate and methane gradients in such sediments (Reeburgh 1980; Iversen and Jørgensen 1985). The process could also be demonstrated with radiolabeled methane in anoxic incubations of sediment samples. Zehnder and Brock (1979) showed by similar experiments that methanogenic bac teria were responsible for this oxidation of labeled methane and that methane oxidation and formation proceeded simulta neously. However, in their assays, methane production always exceeded methane oxidation by two to three orders of magni tude, and thus this process could hardly explain the net methane oxidation observed in sediments.

From a thermodynamic point of view, sulfate dependent methane oxidation is an exergonic reaction

$$
\mathrm{CH}_{4}+\mathrm{SO}_{4}^{2}+2 \mathrm{H}^{+} \rightarrow \mathrm{CO}_{2}+\mathrm{H}_{2} \mathrm{~S}+2 \mathrm{H}_{2} \mathrm{O}
$$

which yields under standard conditions a $\Delta \mathrm{G}_{0}{ }^{\prime}$ of $-18 \mathrm{~kJ}$ per mol. Concentrations of the reaction partners in situ in the active sediment layers are in the range of $10^{-2}$ bar methane and $13 \mathrm{mM}$ of both sulfate and free hydrogen sulfide. Thus, the overall energetics become only slightly more favorable if in situ conditions are taken into consideration. This amount of energy can feed only one bacterium, provided that the bacterium is able to exploit this biological minimum energy quantum. Based on the observation that methanogens can catalyze an oxygen independent methane oxidation (Zehnder and Brock 1979) and the description of a reversal of homoacetogenic fermenta tion by strain AOR and others (see above; $\boldsymbol{\nabla}$ Table 21.3), it was speculated that "reversed methanogenesis" may be the key to an understanding of this process (Hoehler et al. 1994; Schink 1997). If the overall reaction is actually a syntrophic cooperation involving a methanogen running methane formation backward and a sulfate reducing bacterium, it is obvious that only one of the partners can gain metabolic energy from the reaction, and the other one has to run this process only as a cometabolic activity. This would explain at least why scientists have always failed to enrich for methane oxidizing sulfate reducers in the past, simply because one cannot enrich for a bacterium on the basis of a cometabolic activity.

Through the last 10 years, our picture of anaerobic methane oxidation has developed dramatically (Valentine and Reeburgh 2000). Analysis of lipids of marine archaea and sulfate reducing bacteria in anoxic sediment layers indicated that these organisms fed on $\left({ }^{13} \mathrm{C}\right.$ depleted) methane (Pancost et al. 2000), and similar findings, combined with molecular population analysis, were reported for archaeal/bacterial communities in marine sedi ments and close to submarine methane seeps and gas hydrates (Hinrichs et al. 1999; Orphan et al. 2001; Thomsen et al. 2001). In sediments overlying methane hydrates off the coast of Oregon, United States, active anaerobic methane oxidation was found to be associated with discrete, spherical microbial aggre gates which consisted, according to fluorescent in situ hybridi zation analysis (FISH), of Methanosarcina like archaea in the center, surrounded by Desulfosarcina related sulfate reducing bacteria (Boetius et al. 2000). The energetics of sulfate dependent methane oxidation at these gas hydrate sites (with methane pressures of about 80 bar) are considerably more favorable than in deep lying marine sediments, and the overall free energy change of the reaction in situ $(-40 \mathrm{~kJ}$ per mol) may really allow sufficient energy conservation and growth for both partners in this cooperation. In the meantime, thus, these aggre gates represent a first model system to understand sulfate dependent methane oxidation as a syntrophic cooperation phe nomenon, but it still needs to be proven whether this model can also be applied to methane oxidation in deep lying, methane poor marine sediments that are being cultivated in the lab at high methane pressures (Nauhaus et al. 2007), and several new examples of syntrophically methane oxidizing associations have been described which are grouped in two different groups, ANME I and ANME II (Nauhaus et al. 2005). The question remains open how the partners involved cooperate. Evidence available so far indicates that neither hydrogen, nor formate, acetate, or methanol is transferred.

\section{“Obligately Syntrophic" Bacteria: Cultivation and Biochemical Studies}

The mutual dependence of partner bacteria in syntrophic asso ciations has caused severe difficulties in the cultivation of such organisms; nonetheless, defined cocultures have been obtained in numerous cases. For isolation, pure cultures of known methanogenic or sulfate reducing partner bacteria are usually provided in excess as a background "lawn" during the cultiva tion and dilution process to isolate the syntrophically fermenting bacterium in defined binary or ternary mixed cul ture. Today, all well described syntrophically fermenting bacte ria can be cultivated also in pure culture with different substrate combinations (see below). Hence, we should no longer talk about "obligately syntrophic bacteria" (because they are not obligately syntrophic) but only about syntrophic relationships or syntrophic conversion processes. 
Many efforts have been made to grow syntrophically fermenting bacteria in the absence of partner bacteria. Removal of hydrogen by nonbiological procedures (low pres sure and gas diffusion through thin membranes) had only little success with ethanol oxidation, and no success at all with fatty acid oxidation. In other cases, hydrogen removal by palladium catalysts spread on either charcoal or $\mathrm{CaCO}_{3}$ surfaces, with alkenes or alkynes as oxidant have shown some success (Mountfort and Kaspar 1986), as did efforts to couple hydrogen release to reoxidation by electrochemically controlled platinum electrodes. Whether a cultivation apparatus maintaining the hydrogen partial pressure at subnanomolar concentrations (Valentine et al. 2000a, b) will hold more prom ise has still to be proven. More successful was the use of fumarate as external electron acceptor in cultivation of syntrophic propi onate degraders (Stams et al. 1993). Today, pure cultures of syntrophically fermenting bacteria of all known metabolic types have been isolated. Typically, this has been accomplished with substrates that are more oxidized than the original one and can be fermented by dismutation. As an example, ethanol oxidizing syntrophs can be grown in pure culture with acetalde hyde analogues such as acetoin or acetylene (Schink 1985a; Eichler and Schink 1986), butyrate or benzoate degrading syntrophs with crotonate (Beaty and McInerney 1987; Zhao et al. 1989; Wallrabenstein et al. 1995a) or with pentenoate as external electron acceptor (Dong et al. 1994a), and syntrophically propionate degrading bacteria with pyruvate (Wallrabenstein et al. 1994) or propionate plus fumarate (Stams et al. 1993). Beyond that, all syntrophic propionate oxidizers (with the exception of Smithella propionica) have been shown to be able also to reduce sulfate, and can be isolated in pure culture with propionate plus sulfate, although they grow only very slowly with this substrate combination (Harmsen et al. 1993, 1995; Wallrabenstein et al. 1994, 1995b).

Biochemical studies with defined cocultures of syntrophically fermenting bacteria have been carried out suc cessfully with cell free extracts prepared by, e.g., lysozyme (Wofford et al. 1986) or mutanolysin (Wallrabenstein and Schink 1994) treatment, which opens selectively only the fermenting bacterium and leaves the methanogenic partner intact, owing to its archaeal cell wall chemistry. In another approach, the partner organisms were separated by centrifuga tion in Percoll gradients before cell disruption and enzyme assays (Beaty et al. 1987).

\section{Homoacetogenic Versus Methanogenic Coupling and the Effect of Temperature}

Under standard conditions, methanogenic hydrogen oxidation yields more energy than homoacetogenic hydrogen oxidation (- Table 21.2), and one would therefore assume that homoacetogens have little chance to compete successfully against methanogens for hydrogen at limiting concentrations. The function of homoacetogens in the complex electron flow scheme depicted in $\mathbf{F}$ Fig. 21.1 remains unclear, therefore, and the general assumption is that they take advantage of their metabolic versatility, which allows them to compete with several partners of various metabolic types, and consume two or more substrates simultaneously (Schink 1994). Such simulta neous utilization of more than one substrate may increase the effective affinity for every single substrate, as studies with Escherichia coli in continuous cultures with multiple substrate supply have proven (Egli 1995; Lendenmann et al. 1996). How ever, there are exceptional situations in which homoacetogens may definitively outcompete methanogens in their function as hydrogen consumers in sulfate poor anoxic environments. One such situation may be slightly acidic lake sediments such as that found in Knaack Lake, Wisconsin, United States, where at $\mathrm{pH}$ 6.1 the total electron flow goes through the acetate pool, and no methane is formed by direct $\mathrm{CO}_{2}$ reduction (Phelps and Zeikus 1984). Obviously, hydrogen oxidizing methanogens do not perform sufficiently well under these conditions. Thus, homoacetogens take over their function, however, only at low acetate concentration (at $10^{-4}$ bar $\mathrm{H}_{2}$ and $10 \mu \mathrm{M}$ acetate); homoacetogenic hydrogen oxidation yields a $\Delta \mathrm{G}$ of $-26 \mathrm{~kJ}$ per mol of acetate and has to be maintained by aceticlastic methanogens.

Temperature is a further effector which improves the ability of homoacetogens to compete successfully against methanogens for hydrogen. At temperatures lower than $20^{\circ} \mathrm{C}$, homoacetogens appear to take over significant parts of hydrogen oxidation in paddy soil and lake sediments (Conrad et al. 1989; Conrad and Wetter 1990). The known species of hydrogen oxidizing methanogens are not significantly active at such temperatures (Zeikus and Winfrey 1976), and homoacetogens appear to be less restricted in this respect. Dominance of homoacetogenesis in the total electron flow is even more expressed in tundra wetland soils at temperatures lower than $10^{\circ} \mathrm{C}$ (Kotsyurbenko et al. 1996). This effect becomes understandable from a look at the temperature dependence of hydrogen dependent methanogenesis and homoacetogenesis. At hydrogen partial pressures lower than $10^{-4}$ bar and acetate concentrations at $10 \mathrm{mM}$, homoacetogenesis reaches at $5^{\circ} \mathrm{C}$ the same energy gain as hydrogen dependent methanogenesis does at $35^{\circ} \mathrm{C}$. Thus, the general scheme of electron flow in methanogenic environ ments ( $\bigcirc$ Fig. 21.1) has to be modified for slightly acidic or for low temperature habitats ( $($ Fig. 21.3a). Under these conditions, there is no significant hydrogen dependent methanogenesis (group 2), and the electrons flow nearly exclusively via acetogenesis and aceticlastic methanogenesis (groups 5 and 3).

The opposite situation emerges at high temperature habitats as discussed already above in the context of syntrophic acetate oxidation. Under these conditions, homoacetogenesis can oper ate in the opposite direction, and the electron flow goes from acetate through the $\mathrm{C} 1$ pool and hydrogen toward methane (> Fig. 21.3b). Thus, the general flow scheme in ( Fig. 21.1 represents kind of an intermediate situation that probably describes the situation of a sewage sludge digestor correctly but has to be modified for high and low temperature situations in the way indicated. 

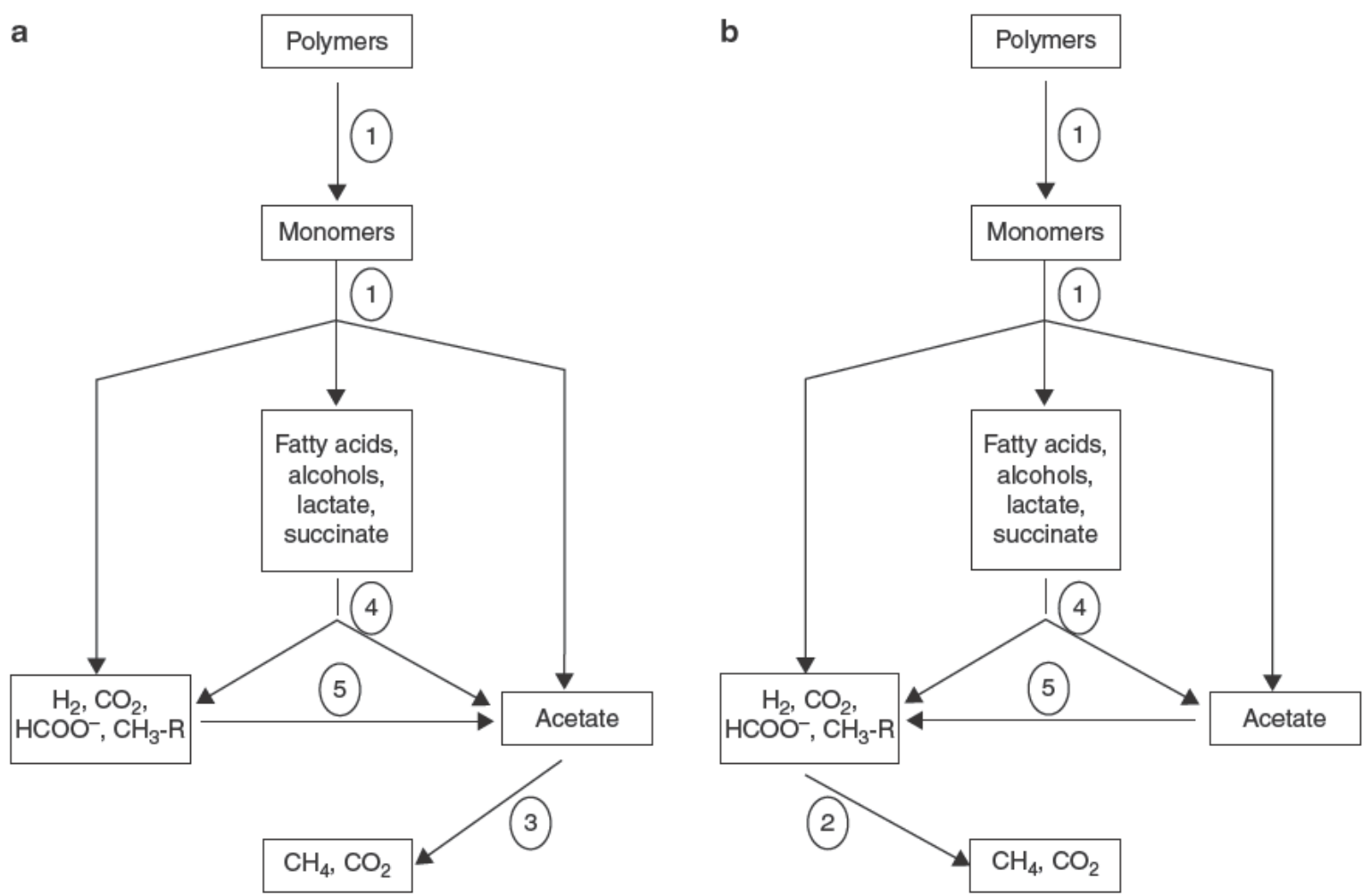

D Fig. 21.3

Carbon and electron flow in methanogenic degradation of complex organic matter. Groups of prokaryotes involved: 1 primary fermentative bacteria, 2 hydrogen-oxidizing methanogens, 3 acetate-cleaving methanogens, 4 secondary fermenting bacteria (syntrophs), and 5 homoacetogenic bacteria. Carbon and electron flow (a) at low temperature and (b) at high temperature

\section{Structure and Growth Dynamics of Syntrophic Associations}

The separation of metabolic functions and their distribution within metabolically different microorganisms, i.e., substrate oxidation and hydrogen formation in the one and hydrogen oxidation and $\mathrm{CO}_{2}$ reduction in the other organism, is a rather unusual strategy that we do not observe, at least not to this extent, in oxic environments. It may have its advantages because it allows a high degree of metabolic specialization to the single organisms concerned, which requires very little effort into refined regulation of energy metabolism. However, the meta bolic efficiency of such cooperating communities depends on an efficient metabolite transfer between the partners involved: The flux of, e.g., hydrogen between the hydrogen forming fermenter and the hydrogen consuming methanogen is inversely propor tional to the distance between both (Schink and Thauer 1988). Optimal metabolite transfer can be achieved best when both partners are in close contact (i.e., directly attached to each other, forming an aggregate or floc). Such flocs form preferen tially in anaerobic digestors in which fatty acids are degraded, although the establishment of stable floc formation may require substantial amounts of time, sometimes even several months after start up (Lettinga et al. 1988). Indirect evidence of aggregate formation in sediments and sludges has been obtained on the basis of hydrogen exchange measurements
(Conrad et al. 1985, 1986), and the recently discovered aggre gates involved in sulfate dependent methane formation (Boetius et al. 2000) exhibit even a high degree of spatial organization.

Efforts to synthesize stable aggregates (granules) of micro biologically defined composition from pure cultures have been made, and the success depended very specifically on the type of partners used. Butyrate degrading aggregates with only two partners were stable only with Methanobacterium formicicum, not with Methanospirillum hungatei, whereas propionate degrading granules depended on the additional presence of an acetate degrading partner (Wu et al. 1996). In suspended cul tures, $M$. hungatei is often the dominant hydrogen utilizer, but it is obviously not the ideal partner for formation of efficient granules. This experiment demonstrates again that our enrich ment and cultivation techniques influence to a high degree the results obtained and may give a rather incorrect picture of the situation prevailing in the natural or seminatural system. The composition and stability of the formed granules are further influenced by the fact that methanogenic granules in waste degrading reactors have to deal with mixed substrate supplies that add further microbial constituents into the architecture of the resulting granule, including, e.g., sulfate reducing bacteria (Wu et al. 1991). In any case, optimal cooperation will be secured in granules in which the partner organisms are ran domly mixed to near homogeneity, rather than in situations in which the partners form "nests" of identical subpopulations. 

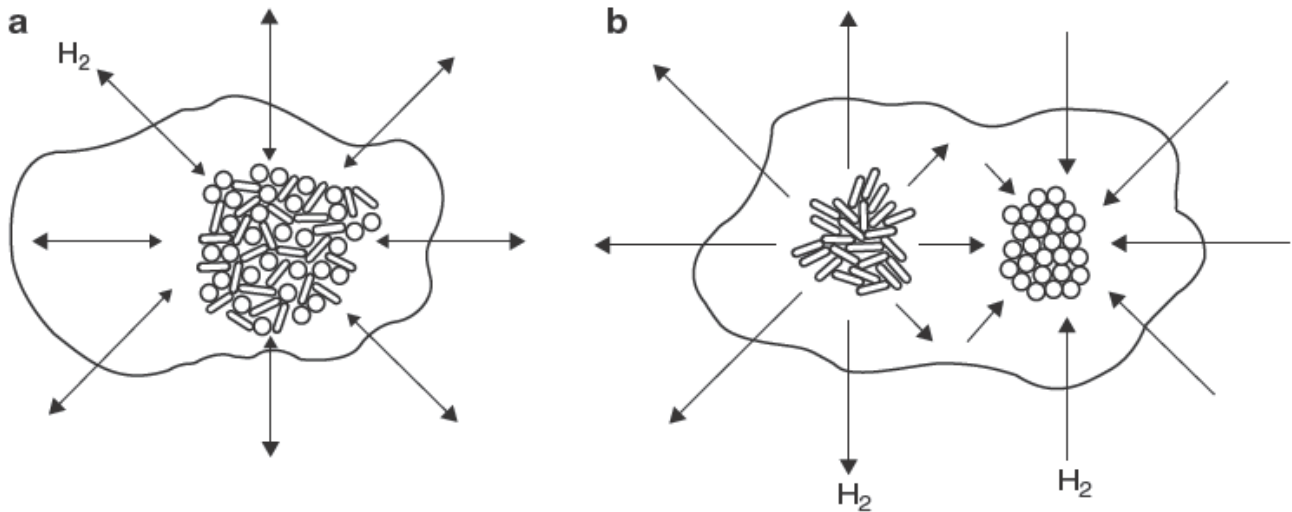

- Fig. 21.4

Exchange of hydrogen (or other intermediates) in anaerobic bacterial flocs containing (a) a homogenously mixed community of hydrogen formers and hydrogen consumers or (b) hydrogen producers and hydrogen consumers in spatially separated nests

A basic problem remains in that each partner bacterium multiplies and produces offspring only of its own kind. Thus, the situation given in $\mathbf{0}$ Fig. 21.4a will change after several generations into one similar to that depicted in $\mathbf{O}$ Fig. 21.4b, and the efficiency of metabolite transfer will decrease with age of the aggregates unless there are ways of internal mixing of the aggregates. Thin sections of methanogenic granules have shown examples of fully mixed as well as of nest structures (Dubourgier et al. 1988), and similar pictures were recently obtained with thin sections in which the partner bacteria were identified by specif ically RNA directed probes (Harmsen et al. 1996). The largely segregated arrangement of the two partners in the spherical aggregates active in syntrophic sulfate dependent methane oxi dation (Boetius et al. 2000) probably represents a terminal stage in the growth of these partners, and the rather regular size of these aggregates indicates that it is limited by metabolite diffu sion kinetics. The dynamics of growth and internal structure development in syntrophic aggregates appears to be an interest ing object of research now that gene probes provide excellent tools for direct in situ identification of the various microbial components involved. First efforts in this respect have shown that there are clear functional separations between the subpop ulations in granular sludge, especially if also some sulfate is available for fatty acid oxidation (Oude Elferink et al. 1998; Santegoeds et al. 1999). A similar study on syntrophic propio nate oxidizers in thermophilic granular sludge revealed that these organisms were localized mainly in the centers of the granules, closely associated with hydrogen scavenging methanogens (Imachi et al. 2000).

It may be worth mentioning in this context that the observed maximum specific growth rates of syntrophic amino acid degrading associations are much lower than those of other amino acid fermenting bacteria. For example, the $\mu_{\max }$ of Clos tridium sp. growing on glutamate is $0.30 .6 \mathrm{~h}^{-1}$ (Laanbroek et al. 1979) and that of S. acidaminophila is $0.13 \mathrm{~h}^{-1}$ (Nanninga et al. 1987). These bacteria use a butyric acid and propionic acid fermentation for the degradation of glutamate, respectively. However, the $\mu_{\max }$ of $A$. hydrogenoformans growing on glutamate in syntrophic association with a hydrogenotrophic anaerobe is only $0.10 \mathrm{~h}^{-1}$. The $\mu_{\max }$ of a Campylobacter sp. growing on aspartate is about $0.17 \mathrm{~h}^{-1}$ (Laanbroek et al. 1978), whereas the $\mu_{\max }$ of a coculture of E. acidaminophilum and a methanogen is below $0.1 \mathrm{~h}^{-1}$ (Zindel et al. 1988). Nevertheless, in environments with a high methanogenic activity, e.g., granular sludge from anaerobic bioreactors, high numbers of bacteria can be counted which grow syntrophically with methanogens. Three explanations can be given for this: (1) the growth rates of the syntrophic associations at low substrate concentrations are higher than those of other amino acid fermenting bacteria, i.e., the syntrophic associations have a higher affinity for the substrate; (2) the syntrophic associations grow on mixtures of substrates rather than on single substrates; and (3) the growth rates of the syntrophic associations are higher than the ones that have been measured. The reported growth rates of the cocultures refer to suspended growth, whereas in methanogenic biofilms and aggre gates, growth rates might be much higher because of the shorter interbacterial distances. These observations give further support to the assumption that the growth rates of syntrophic associations are limited by the rate of interspecies metabolite transfer.

\section{Cooperation with Protozoa, Hydrogenosomes}

The function of the primary fermenting bacteria (group 1) in conversion of complex organic matter to methane and $\mathrm{CO}_{2}$ (ङ Fig. 21.1) may be taken over also by eukaryotic organisms. Anaerobic fungi, ciliates and flagellates, are known to thrive in entirely anoxic environments under reducing conditions (Finlay and Fenchel 1992; Fenchel and Finlay 1995), and some of them are extremely oxygen sensitive. Since aerobic respiration is not possible in such habitats, anaerobic protozoa do not contain mitochondria. Instead, intracellular organelles are present which release hydrogen and have been called "hydrogenosomes." The metabolism of these protozoa is fermentative; particles, espe cially bacterial cells, are ingested into food vacuoles and digested 
by hydrolysis and further fermentation, and acetate is probably the most important fermentation product.

Anaerobic protozoa can be associated with symbiotic methanogens, either extracellularly or intracellularly. Ciliates liv ing in strictly anoxic, eutrophic sediments carry methanogenic partner bacteria inside the cell (van Bruggen et al. 1983, 1985), often closely associated with the hydrogenosomes. The advan tage of this cooperation with hydrogenotrophic methanogens for the protozoan host is obvious: Removal of hydrogen and maintenance of a low hydrogen/formate concentration in the cell allow fermentation of complex organic matter mainly to acetate and $\mathrm{CO}_{2}$. Thus, waste of organic precursors into reduced end products such as ethanol, fatty acids, etc. can be avoided, and the fermenting protozoon obtains a maximum ATP yield. The symbiotic methanogen takes over part of the function that mitochondria have in aerobic higher cells. Reducing equivalents are removed by the symbiotic partner, and the eukaryotic host cell runs a fermentative metabolism with maximum ATP yield.

It is assumed that the hydrogen released by hydrogenosomes stems mainly from pyruvate oxidation to acetyl CoA (pyruvate synthase reaction; Müller 1988). Hydrogenosomes contain this enzyme, as well as ferredoxin and hydrogenase. In some cases, especially with the larger types of anaerobic protozoa, close associations of methanogenic endosymbionts with hydrogenosomes have been observed. Smaller protozoa may achieve the same effect of hydrogen release also with extracellu lar partner bacteria because the diffusion distance to the surface may be short enough. The same applies to the rumen ciliates which in their comparably rich habitat cooperate only occasionally with symbiotic partners on their cell surface (Stumm et al. 1982).

Hydrogenosome and methanogenic endosymbiont together form a functional entity. In some cases, especially with the comparably big ciliates such as Plagiopyla frontata, hydrogenosomes and methanogens are organized in an alternat ing sandwich arrangement that allows optimal hydrogen trans fer in highly refined structures (Finlay and Fenchel 1992). It has been speculated that hydrogenosomes of strictly anaerobic pro tozoa have evolved from the mitochondria of their aerobic pre decessors; other speculations assume a relationship of hydrogenosomes to clostridia. The high structural development of hydrogenosomes in some protozoa may suggest that such arrangements could operate also in transfer of hydrogen from less easily available electron donors than the pyruvate synthase system represents. Unfortunately, detailed studies on the coop eration of methanogenic endosymbionts with their protozoan hosts have been hampered so far by extreme difficulties in handling defined cultures of strictly anaerobic protozoa.

\section{Taxonomy of Syntrophs}

The survey of described bacteria active in syntrophic oxidation of alcohols, fatty acids, and aromatic compounds (8 Table 21.4) documents that these bacteria are found only in two groups within the taxonomic system based on sequence similarities of the $16 \mathrm{~S}$ rRNA, namely, the Gram positive bacteria with low $\mathrm{G}+\mathrm{C}$ content and the $\Delta$ proteobacteria. Some meta bolic specializations are clustered in certain taxonomic groups, e.g., ethanol, propionate, and benzoate oxidation in the $\Delta$ proteobacteria (with the exception of Thermoanaerobium brockii), or fatty acid $\beta$ oxidation and acetate oxidation in the Gram positive bacteria with low $\mathrm{G}+\mathrm{C}$ content. Nonetheless, these groups are not really homogenous but encompass repre sentatives of many other metabolic types, e.g., sulfate reducers that do not exhibit any tendency to transfer electrons to partner organisms. Finally, as pointed out above, the fermentative deg radation of amino acids includes so many different expressions of obligate and facultative syntrophy within taxonomically extremely different groups of organisms that syntrophy can hardly be assumed to be associated with a single evolutionary trait. Rather, syntrophy appears to be kind of a lifestyle that is experienced and perfected by many different organisms to vary ing extents.

\section{Conclusions}

The energetics of syntrophic fatty acid and alcohol oxidizing processes represent exciting examples of energy metabolism based on the smallest energy quantum that, to our present understanding, can be exploited by living cells. This minimum amount of energy which can be converted into ATP in the living cell is in the range of $-20 \mathrm{~kJ}$ per reaction run or even lower, and this is the amount of energy available to the respective partners in most of the degradation processes discussed here. Models of metabolic cooperation and energy sharing between syntrophic partners can be based on this assumption, and experimental evidence of reverse electron transport systems to balance the energy requirements for hydrogen release have been obtained in several instances.

Recent studies on the biochemistry of syntrophic fatty acid oxidizers revealed that these bacteria are by no means "primi tive" but actually admirable creatures from the point of view of energy conservation and efficient energy utilization. Most of these bacteria grow in plain mineral media and synthesize all their cellular components on the basis of only the minimum quantum of energy which can be exploited by living cells at all. They are spectacular examples of how diligently nature has organized the components of global energy flux down to those environments where very little energy is available to their living inhabitants.

\section{Acknowledgments}

The authors express their gratitude to Marvin P. Bryant, Ralph Wolfe, Norbert Pfennig, Rudolf Thauer, Fritz Widdel, Alex Zehnder, and Ralf Conrad for numerous fruitful discussions about the biology and energetics of syntrophic anaerobes and to their former and present coworkers for their dedicated work on these extremely fastidious bacteria. 


\section{References}

Ahring BK, Westermann P (1988) Product inhibition of butyrate metabolism by acetate and hydrogen in a thermophilic coculture. Appl Environ Microbiol 54:2393-2397

Auburger G, Winter J (1992) Purification and characterization of benzoyl-CoA ligase from a syntrophic, benzoate-degrading, anaerobic mixed culture. Appl Microbiol Biotechnol 37:789-795

Baena S, Fardeau M-L, Labat M, Ollivier B, Garcia J-L, Patel BKC (1998) Aminobacterium colombiense, gen. nov., sp. nov., an amino acid degrading anaerobe isolated from anaerobic sludge. Anaerobe 4:241-250

Baena S, Fardeau M-L, Ollivier B, Labat M, Thomas P, Garcia J-L, Patel BKC (1999a) Aminomonas paucivorans gen. nov., sp. nov., a mesophilic, anaerobic, amino-acid-utilizing bacterium. Int J Syst Bacteriol 49:975-982

Baena S, Fardeau M-L, Woo THS, Ollivier B, Labat M, Patel BKC (1999b) Phylogenetic relationships of three amino-acid-utilizing anaerobes, Selenomonas acidaminovorans, "Selenomonas acidaminophila" and Eubacterium acidaminophilum, as inferred from partial 16S rDNA nucleotide sequences and proposal of Thermanaerovibrio acidaminovorans gen. nov., comb. nov. and Anaeromusa acidaminophila gen. nov, comb. nov. Int J Syst Bacteriol 49:969-974

Baena S, Fardeau M-L, Labat M, Ollivier B, Garcia BJ-L, Patel BKC (2000) Aminobacterium mobile, sp. nov., a new anaerobic amino-aciddegrading bacterium. Int J Syst Evol Microbiol 50:259-264

Barik S, Brulla WJ, Bryant MP (1985) PA-1, a versatile anaerobe obtained in pure culture, catabolizes benzenoids and other compounds in syntrophy with hydrogenotrophs, and P-2 plus Wolinella sp. degrades benzenoids. Appl Environ Microbiol 50:304-310

Barker HA (1940) Studies upon the methane fermentation. IV: The isolation and culture of Methanobacterium omelianskii. Ant $\mathrm{v}$ Leeuwenhoek 6:201-220

Barker HA (1981) Amino acid degradation by anaerobic bacteria. Annu Rev Biochem 50:23-40

Beaty PS, McInerney MJ (1987) Growth of Syntrophomonas wolfei in pure cultures on crotonate. Arch Microbiol 147:389-393

Beaty PS, McInerney MJ (1989) Effect of organic acid anions on the growth and metabolism of Syntrophomonas wolfei in pure culture and in defined consortia. Appl Environ Microbiol 55:977-983

Beaty PS, Wofford NQ, McInerney MJ (1987) Separation of Syntrophomonas wolfei from Methanospirillum hungatei in syntrophic cocultures by using Percoll gradients. Appl Environ Microbiol 53:1183-1185

Ben-Bassat A, Lamed R, Zeikus JG (1981) Ethanol production by thermophilic bacteria: metabolic control of end product formation in Thermoanaerobium brockii. J Bacteriol 146:192-199

Biebl H, Pfennig N (1978) Growth yields of green sulfur bacteria in mixed cultures with sulfur and sulfate reducing bacteria. Arch Microbiol 117:9-16

Bleicher K, Winter J (1994) Formate production and utilization by methanogens and by sewage sludge consortia-interference with the concept of interspecies formate transfer. Appl Microbiol Biotechnol 40:910-915

Boetius A, Ravenschlag K, Schubert CJ, Rickert D, Widdel F, Giesecke A, Amann R, Jorgensen BB, Witte U, Pfannkuche O (2000) A marine microbial consortium apparently mediating anaerobic oxidation of methane. Nature 407:623-626

Boone DR, Bryant MP (1980) Propionate-degrading bacterium, Syntrophobacter wolinii sp. nov. gen. nov., from methanogenic ecosystems. Appl Environ Microbiol 40:626-632

Boone DR, Johnson RL, Liu Y (1989a) Diffusion of the interspecies electron carriers $\mathrm{H}_{2}$ and formate in methanogenic ecosystems, and implications in the measurement of $\mathrm{K}_{\mathrm{M}}$ for $\mathrm{H}_{2}$ or formate uptake. Appl Environ Microbiol 55:1735-1741

Boone DR, Johnson RL, Liu Y (1989b) Microbial ecology of interspecies hydrogen and formate transfer in methanogenic ecosystems. In: Hattori T, Ishida Y, Maruyama Y, Morita RY, Uchida A (eds) Recent advances in microbial ecology. Japan Scientific Society Press, Tokyo, pp 450-453

Bryant MP (1979) Microbial methane production-theoretical aspects. J Anim Sci 48:193-201
Bryant MP, Wolin EA, Wolin MJ, Wolfe RS (1967) Methanobacillus omelianskii, a symbiotic association of two species of bacteria. Arch Mikrobiol 59:20-31 Bryant MP, Campbell LL, Reddy CA, Crabill MR (1977) Growth of Desulfovibrio in lactate or ethanol media low in sulfate in association with $\mathrm{H}_{2}$-utilizing methanogenic bacteria. Appl Environ Microbiol 33:1162-1169

Buckel W, Barker HA (1974) Two pathways of glutamate fermentation by anaerobic bacteria. J Bacteriol 117:1248-1260

Cervantes FJ, van der Velde S, Lettinga G, Field JA (2000) Quinones as terminal electron acceptors for anaerobic microbial oxidation of phenolic compounds. Biodegradation 11:313-321

Chen SY, Liu XL, Dong XZ (2005) Syntrophobacter sulfatireducens sp. nov., a novel syntrophic, propionate-oxidizing bacterium isolated from UASB reactors. Int J Syst Evol Microbiol 55:1319-1324

Cheng G, Plugge CM, Roelofsen W, Houwen FP, Stams AJM (1992) Selenomonas acidaminovorans sp. nov., a versatile thermophilic proton-reducing anaerobe able to grow by decarboxylation of succinate to propionate. Arch Microbiol 157:169-175

Cherepanov DA, Mulkidjanian AY, Junge W (1999) Transient accumulation of elastic energy in proton translocating ATP synthase. FEBS Lett 449:1-6

Conrad R, Wetter B (1990) Influence of temperature on energetics of hydrogen metabolism in homoacetogenic, methanogenic, and other anaerobic bacteria. Arch Microbiol 155:94-98

Conrad R, Phelps TJ, Zeikus JG (1985) Gas metabolism evidence in support of the juxtaposition of hydrogen-producing and methanogenic bacteria in sewage sludge and lake sediments. Appl Environ Microbiol 50:595-601

Conrad R, Schink B, Phelps TJ (1986) Thermodynamics of $\mathrm{H}_{2}$-consuming and $\mathrm{H}_{2}$-producing metabolic reactions in diverse methanogenic environments under in situ conditions. FEMS Microbiol Ecol 38:353-360

Conrad R, Bak F, Seitz HJ, Thebrath B, Mayer HP, Schutz H (1989) Hydrogen turnover by psychrotrophic homoacetogenic and mesophilic methanogenic bacteria in anoxic paddy soil and lake sediment. FEMS Microbiol Ecol 62:285-294

Cord-Ruwisch R, Lovley DR, Schink B (1998) Growth of Geobacter sulfurreducens with acetate in syntrophic cooperation with hydrogen-oxidizing anaerobic partners. Appl Environ Microbiol 64:2232-2236

Daniel R, Warnecke F, Potekhina JS, Gottschalk G (1999) Identification of the syntrophic partners in a coculture coupling anaerobic methanol oxidation to Fe(III) reduction. FEMS Microbiol Lett 180:197-203

De Bok FAM, Stams AJM, Dijkema C, Boone DR (2001) Pathway of propionate oxidation by a syntrophic culture of Smithella propionica and Methanospirillum hungatei. Appl Environ Microbiol 67:1800-1804

de Bok FAM, Luijten MLGC, Stams AJM (2002) Biochemical evidence for formate transfer in syntrophic propionate-oxidizing cocultures of Syntrophobacter fumaroxidans and Methanospirillum hungatei. Appl Environ Microbiol 68:4247-4252

de Bok FAM, Harmsen HJM, Plugge CM, de Vries MC, Akkermans ADL, de Vos WM, Stams AJM (2005) The first true obligately syntrophic propionateoxidizing bacterium, Pelotomaculum schinkii sp. nov., co-cultured with Methanospirillum hungatei, and emended description of the genus Pelotomaculum. Int J Syst Evol Microbiol 55:1697-1703

Dimroth K (1983) Thermochemische Daten organischer Verbindungen. In: Synowietz C (ed) D'Ans-Lax Taschenbuch fur Chemiker und Physiker, vol 2. Springer, Berlin, pp 997-1038

Dimroth P (1987) Sodium transport decarboxylases and other aspects of sodium ion cycling in bacteria. Microbiol Rev 51:320-340

Dimroth P (2000) Operation of the F0 motor of the ATP synthase. Biochem Biophys Acta 1458:374-386

Dolfing J, Jiang B, Henstra AM, Stams AJM, Plugge CM (2008) Syntrophic growth on formate: a new microbial niche in anoxic environments. Appl Environ Microbiol 74:6126-6131

Dong X, Stams AJM (1995a) Evidence for $\mathrm{H}_{2}$ and formate formation during syntrophic butyrate and propionate degradation. Anaerobe 1:35-39

Dong X, Stams AJM (1995b) Localization of enzymes involved in $\mathrm{H}_{2}$ and formate metabolism in Syntrophospora bryantii. Ant v Leeuwenhoek 67:345-350

Dong X, Cheng G, Stams AJM (1994a) Butyrate oxidation by Syntrophospora bryantii in coculture with different methanogens and in pure culture with pentenoate as electron acceptor. Appl Microbiol Biotechnol 42:647-652 
Dong X, Plugge CM, Stams AJM (1994b) Anaerobic degradation of propionate by a mesophilic acetogenic bacterium in coculture and triculture with different methanogens. Appl Environ Microbiol 60:2834-2838

Dorner C (1992) Biochemie und Energetik der Wasserstofffreisetzung in der syntrophen Vergarung von Fettsauren und Benzoat. Thesis, Universitat Tubingen, Tubingen, 58-61

Dubourgier HC, Prensier G, Albagnac G (1988) Structure and microbial activities of granular anaerobic sludge. In: Lettinga G, Zehnder AJB, Grotenhuis JTC, Hulshoff LW (eds) Granular anaerobic sludge: microbiology and technology. Pudoc, Wageningen, pp 18-33

Dwyer DF, Weeg-Aerssens E, Shelton DR, Tiedje JM (1988) Bioenergetic conditions of butyrate metabolism by a syntrophic, anaerobic bacterium in coculture with hydrogen-oxidizing methanogenic and sulfidogenic bacteria. Appl Environ Microbiol 54:1354-1359

Egli T (1995) The ecological and physiological significance of the growth of heterotrophic microorganisms with mixtures of substrates. In: Jones JG (ed) Advances in microbial ecology, vol 14. Plenum, New York, pp 305-386

Eichler B, Schink B (1986) Fermentation of primary alcohols and diols, and pure culture of syntrophically alcohol-oxidizing anaerobes. Arch Microbiol 143:60-66

Elshahed MS, Bhupathiraju VK, Wofford NQ, Nanny MA, McInerney M (2001) Metabolism of benzoate, cyclohex-1-ene carboxylate, and cyclohexane carboxylate by "Syntrophus aciditrophicus" strain SB in syntrophic association with $\mathrm{H}_{2}$-using microorganisms. Appl Environ Microbiol 67:1728-1738

Engelbrecht S, Junge W (1997) ATP synthase: a tentative structural model. FEBS Lett 414:485-491

Fenchel T, Finlay BJ (1995) Ecology and evolution in anoxic worlds. Oxford University Press, Oxford, UK, pp 108-171

Fey A, Conrad R (2000) Effect of temperature on carbon and electron flow and on the archaeal community in methanogenic rice field soil. Appl Environ Microbiol 66:4790-4797

Finlay BJ, Fenchel T (1992) Methanogens and other bacteria as symbionts of freeliving anaerobic ciliates. Symbiosis 14:375-390

Friedrich M, Schink B (1993) Hydrogen formation from glycolate driven by reversed electron transport in membrane vesicles of a syntrophic glycolateoxidizing bacterium. Eur J Biochem 217:233-240

Friedrich M, Schink B (1995) Electron transport phosphorylation driven by glyoxylate respiration with hydrogen as electron donor in membrane vesicles of a glyoxylate-fermenting bacterium. Arch Microbiol 163:268-275

Friedrich M, Laderer U, Schink B (1991) Fermentative degradation of glycolic acid by defined syntrophic cocultures. Arch Microbiol 156:398-404

Friedrich M, Springer N, Ludwig W, Schink B (1996) Phylogenetic position of Desulfofustis glycolicus gen. nov. sp. nov. and Syntrophobotulus glycolicus gen. nov. sp. nov., two strict anaerobes growing with glycolic acid. Int J Syst Bacteriol 46:1065-1069

Fuchs GM, Mohamed ES, Altenschmidt U, Roch J, Lach A, Brackmann R, Lockmeyer C, Oswald B (1994) Biochemistry of anaerobic biodegradation of aromatic compounds. In: Ratledge C (ed) Biochemistry of microbial degradation. Kluwer, Dordrecht, pp 513-553

Fukuzaki S, Nishio N, Shobayashi M, Nagai S (1990) Inhibition of the fermentation of propionate to methane by hydrogen, acetate, and propionate. Appl Environ Microbiol 56:719-723

Girbal L, Ørlygsson J, Reinders BJ, Gottschal JC (1997) Why does Clostridium acetireducens not use interspecies hydrogen transfer for growth on leucine? Curr Microbiol 35:155-160

Gorby YA, Yanina S, McLean JS, Rosso KM, Moyles D, Dohnalkova A, Beveridge TJ, Chang IS, Kim BH, Kim KS, Culley DE, Reed SB, Romine MF, Saffarini DA, Hill EA, Shi L, Elias DA, Kennedy DW, Pinchuk G Watanabe K, Ishii S, Logan B, Nealson KH, Fredrickson JK (2006) Electrically conductive bacterial nanowires produced by Shewanella oneidensis strain MR-1 and other microorganisms. Proc Natl Acad Sci USA 103:11358-11363

Gottschalk G (1986) Bacterial metabolism, 2nd edn. Springer, New York

Harmsen H, Wullings B, Akkermans ADL, Ludwig W, Stams AJM (1993) Phylogenetic analysis of Syntrophobacter wolinii reveals a relationship with sulfate-reducing bacteria. Arch Microbiol 160:238-240
Harmsen HJM, Kengen HMP, Akkermans ADL, Stams AJM (1995) Phylogenetic analysis of two syntrophic propionate-oxidizing bacteria in enrichment cultures. Syst Appl Microbiol 18:67-73

Harmsen HJM, Kengen HMP, Akkermans ADL, Stams AJM, de Vos WM (1996) Detection and localization of syntrophic propionate-oxidizing bacteria in granular sludge by in situ hybridization using $16 \mathrm{~S}$ rRNA-based oligonucleotide probes. Appl Environ Microbiol 62:1656-1663

Harmsen HJ, Van Kuijk BL, Plugge CM, Akkermans AD, De Vos WM, Stams AJ (1998) Syntrophobacter fumaroxidans sp. nov., a syntrophic propionatedegrading sulfate-reducing bacterium. Int J Syst Bacteriol 48:1383-1387

Hattori S, Kamagata Y, Hanada S, Shoun H (2000) Thermacetogenium phaeum gen. nov., sp. nov., a strictly anaerobic, thermophilic, syntrophic acetateoxidizing bacterium. Int J Syst Evol Microbiol 50:1601-1609

Hattori S, Galushko AS, Kamagata Y, Schink B (2005) Operation of the CO dehydrogenase/acetyl-CoA pathway in both acetate oxidation and acetate formation by the syntrophically acetate-oxidizing bacterium Thermacetogenium phaeum. J Bacteriol 187:3471-3476

Heider J, Fuchs G (1997) Anaerobic metabolism of aromatic compounds. Eur J Biochem 243:577-596

Herrmann G, Jayamani E, Mai G, Buckel W (2008) Energy conservation via electron-transferring flavoprotein in anaerobic bacteria. J Bacteriol 190:784-791

Hinrichs KU, Hayes JM, Sylva SP, Brewer PG, DeLong EF (1999) Methaneconsuming archaebacteria in marine sediments. Nature 398:802-805

Hoehler TM, Alperin MJ, Albert DB, Martens CS (1994) Field and laboratory studies of methane oxidation in an anoxic marine sediment: evidence for a methanogen-sulfate reducer consortium. Global Biochem Cycles $8: 451-463$

Hoehler TM, Alperin MJ, Albert DB, Martens CS (2001) Apparent minimum free energy requirements for methanogenic Archaea and sulfate-reducing bacteria in an anoxic marine sediment. FEMS Microbiol Ecol 38:33-41

Houwen FP, Dijkema C, Schoenmakers CHH, Stams AJM, Zehnder AJB (1987) ${ }^{13}$ C-NMR study of propionate degradation by a methanogenic coculture. FEMS Microbiol Lett 41:269-274

Houwen FP, Plokker J, Stams AJM, Zehnder AJB (1990) Enzymatic evidence for involvement of the methylmalonyl-CoA pathway in propionate oxidation by Syntrophobacter wolinii. Arch Microbiol 155:52-55

Imachi H, Sekiguchi Y, Kamagata Y, Ohashi A, Harada H (2000) Cultivation and in situ detection of a thermophilic bacterium capable of oxidizing propionate in syntrophic association with hydrogenotrophic methanogens in a thermophilic methanogenic granular sludge. Appl Environ Microbiol 66:3608-3615

Imachi H, Sakai S, Ohashi A, Harada H, Hanada S, Kamagata Y, Sekiguchi Y (2007) Pelotomaculum propionicicum sp. nov., an anaerobic, mesophilic, obligately syntrophic, propionate-oxidizing bacterium. Int J Syst Evol Microbiol 57:1487-1492

Iversen N, Jørgensen BB (1985) Anaerobic methane oxidation rates at the sulfatemethane transition in marine sediments from Kattegat and Skagerrak (Denmark). Limnol Oceanogr 30:944-955

Jackson BE, Bhupathiraju VK, Tanner RS, Woese CR, McInerney MJ (1999) Syntrophus aciditrophicus sp. nov., a new anaerobic bacterium that degrades fatty acids and benzoate in syntrophic association with hydrogen-using microorganisms. Arch Microbiol 171:107-114

Kaden J, Galushko AS, Schink B (2002) Cysteine-mediated electron transfer in syntrophic acetate oxidation by cocultures of Geobacter sulfurreducens and Wolinella succinogenes. Arch Microbiol 178(1):53-58

Koch M, Dolfing J, Wuhrmann K, Zehnder AJB (1983) Pathway of propionate degradation by enriched methanogenic cultures. Appl Environ Microbiol 45:1411-1414

Kosaka T, Kato S, Shimoyama T, Ishii S, Abe T, Watanabe K (2008) The genome of Pelotomaculum thermopropionicum reveals niche-associated evolution in anaerobic microbiota. Genome Res 18:442-448

Kosaka T, Uchiyama T, Ishii S, Enoki M, Imachi H, Kamagata Y, Ohashi A, Harada H, Ikenaga H, Watanabe K (2006) Reconstruction and regulation of the central catabolic pathway in the thermophilic propionateoxidizing syntroph Pelotomaculum thermopropionicum. J Bacteriol 188:202-210 
Kotsyurbenko OR, Nozhevnikova AN, Soloviova TI, Zavarzin GA (1996) Methanogenesis at low temperatures by microflora of tundra wetland soil. Ant v Leeuwenhoek 69:75-86

Kremer DR, Nienhuis-Kuiper HE, Hansen TA (1988) Ethanol dissimilation in Desulfovibrio. Arch Microbiol 150:552-557

Kung JW, Loffler C, Dorner K, Heintz D, Gallien S, Van Dorsselaer A, Friedrich T, Boll M (2009) Identification and characterization of the tungsten-containing class of benzoyl-coenzyme A reductases. Proc Natl Acad Sci USA 106:17687-17692

Kung JW, Baumann S, von Bergen M, Muller M, Hagedoorn PL, Hagen WR, Boll M (2010) Reversible biological Birch reduction at an extremely low redox potential. J Am Chem Soc 132:9850-9856

Laanbroek HJ, Stal LJ, Veldkamp H (1978) Utilization of hydrogen and formate by Campylobacter spec. under aerobic and anaerobic conditions. Arch Microbiol 119:99-102

Laanbroek HJ, Smit AJ, Klein-Nulend G, Veldkamp H (1979) Competition for glutamate between specialized and versatile Clostridium species. Arch Microbiol 120:330-335

Lee MJ, Zinder SH (1988a) Carbon monoxide pathway enzyme activities in a thermophilic anaerobic bacterium grown acetogenically and in a syntrophic acetate-oxidizing coculture. Arch Microbiol 150:513-518

Lee MJ, Zinder SH (1988b) Hydrogen partial pressures in a thermophilic acetateoxidizing methanogenic cocultures. Appl Environ Microbiol 54:1457-1461

Lee MJ, Zinder SH (1988c) Isolation and characterization of a thermophilic bacterium which oxidizes acetate in syntrophic association with a methanogen and which grows acetogenically on $\mathrm{H}_{2}-\mathrm{CO} \mathrm{H}_{2}$. Appl Environ Microbiol 54:124-129

Lendenmann U, Snozzi M, Egli T (1996) Kinetics of the simultaneous utilization of sugar mixtures by Escherichia coli in continuous culture. Appl Environ Microbiol 62:1493-1499

Lettinga G, Zehnder AJB, Grotenhuis JTC, Hulshoff LW (eds) (1988) Granular anaerobic sludge: microbiology and technology. Pudoc, Wageningen

Liu Y, Balkwill DL, Aldrich HC, Drake GR, Boone DR (1999) Characterization of the anaerobic propionate-degrading syntrophs Smithella propionica gen. nov., sp. nov. and Syntrophobacter wolinii. Int J Syst Bacteriol 49:545-556

Loffler C, Kuntze K, Vazquez JR, Rugor A, Kung JW, Bottcher A, Boll M (2011) Occurrence, genes and expression of the W/Se-containing class II benzoyl-coenzyme A reductases in anaerobic bacteria. Environ Microbiol 13:696-709

Lovley DR, Coates JD, Blunt-Harris EL, Phillips EJP, Woodward JC (1996) Humic substances as electron acceptors for microbial respiration. Nature 382:445-448

Matthies C, Schink B (1992) Reciprocal isomerization of butyrate and isobutyrate by strain WoGl3, and methanogenic isobutyrate degradation by a defined triculture. Appl Environ Microbiol 58:1435-1439

Matthies C, Schink B (1993) Anaerobic degradation of long-chain dicarboxylic acids by methanogenic enrichment cultures. FEMS Microbiol Lett 111:177-182

McInerney MJ (1988) Anaerobic hydrolysis and fermentation of fats and proteins. In: Zehnder AJB (ed) Biology of anaerobic microorganisms. Wiley, New York, pp 373-415

McInerney MJ, Wofford NQ (1992) Enzymes involved in crotonate metabolism in Syntrophomonas wolfei. Arch Microbiol 158:344-349

McInerney MJ, Bryant MP, Pfennig N (1979) Anaerobic bacterium that degrades fatty acids in syntrophic association with methanogens. Arch Microbiol 122:129-135

McInerney MJ, Bryant MP, Hespell RB, Costerton JW (1981) Syntrophomonas wolfei gen. nov. sp. nov., an anaerobic, syntrophic, fatty acid-oxidizing bacterium. Appl Environ Microbiol 41:1029-1039

McInerney MJ, Rohlin L, Mouttaki H, Kim U, Krupp RS, Rios-Hernandez L, Sieber J, Struchtemeyer CG, Bhattacharyya A, Campbell JW, Gunsalus RP (2007) The genome of Syntrophus aciditrophicus: life at the thermodynamic limit of microbial growth. Proc Natl Acad Sci USA 104:7600-7605

McInerney MJ, Struchtemeyer CG, Sieber J, Mouttaki H, Stams AJM, Schink B, Rohlin L, Gunsalus RP (2008) Physiology, ecology, phylogeny, and genomics of microorganisms capable of syntrophic metabolism. Ann N Y Acad Sci 1125:58-72
Meckenstock RU (1999) Fermentative toluene degradation in anaerobic defined syntrophic cocultures. FEMS Microbiol Lett 177:67-73

Meijer WG, Nienhuis-Kuiper ME, Hansen TA (1999) Fermentative bacteria from estuarine mud: phylogenetic position of Acidaminobacter hydrogenoformans and description of a new type of Gram-negative, propionigenic bacterium as Propionibacter pelophilus gen. nov., sp. nov. Int J Syst Bacteriol 49:1039-1044

Mitchell P (1966) Chemiosmotic coupling in oxidative and photosynthetic phosphorylation. Biol Rev Camb Phil Soc 41:445-502

Mountfort DO, Bryant MP (1982) Isolation and characterization of an anaerobic syntrophic benzoate-degrading bacterium from sewage sludge. Arch Microbiol 133:249-256

Mountfort DO, Kaspar HF (1986) Palladium-mediated hydrogenation of unsaturated hydrocarbons with hydrogen gas released during anaerobic cellulose degradation. Appl Environ Microbiol 52:744-750

Muller M (1988) Energy metabolism of protozoa without mitochondria. Annu Rev Microbiol 42:465-488

Muller N, Stingl U, Griffin BM, Schink B (2008) Dominant sugar utilizers in sediment of Lake Constance depend on syntrophic cooperation with methanogenic partner organisms. Environ Microbiol 10:1501-1511

Muller N, Schleheck D, Schink B (2009) Involvement of NADH: acceptor oxidoreductase and butyryl-CoA dehydrogenase in reversed electron transport during syntrophic butyrate oxidation by Syntrophomonas wolfei. J Bacteriol 191:6167-6177

Muller N, Worm P, Schink B, Stams AJM, Plugge CM (2010) Syntrophic butyrate and propionate oxidation processes: from genomes to reaction mechanisms. Environ Microbiol Rep 2:489-499

Nagase M, Matsuo T (1982) Interaction between amino-acid degrading bacteria and methanogenic bacteria in anaerobic digestion. Biotechnol Bioeng 24:2227-2239

Nanninga HJ, Gottschal JC (1985) Amino acid fermentation and hydrogen transfer in mixed cultures. FEMS Microbiol Ecol 31:261-269

Nanninga HJ, Drent WJ, Gottschal JC (1987) Fermentation of glutamate by Selenomonas acidaminophila sp. nov. Arch Microbiol 147:152-157

Nauhaus K, Treude T, Boetius A, Kruger M (2005) Environmental regulation of the anaerobic oxidation of methane: a comparison of ANME-I and ANME-II communities. Environ Microbiol 7:98-106

Nauhaus K, Albrecht M, Elvert M, Boetius A, Widdel F (2007) In vitro cell growth of marine archaeal-bacterial consortia during anaerobic oxidation of methane with sulphate. Environ Microbiol 9:187-196

Naumann E, Hippe H, Gottschalk G (1983) Betaine: new oxidant in the Stickland reaction and methanogenesis from betaine and L-alanine by a Clostridium sporogenes-Methanosarcina barkeri coculture. Appl Environ Microbiol 45:474-483

Ørlygsson J (1994) The role of interspecies hydrogen transfer on thermophilic protein and amino acid metabolism. PhD thesis, Swedish University of Agricultural Sciences, Uppsala (Chap 4)

Ørlygsson J, Houwen FP, Svensson BH (1993) Anaerobic degradation of protein and the role of methane formation in steady state thermophilic enrichment cultures. Swed J Agric Res 23:45-54

Orphan VJ, Hinrichs K-U, Ussler W, Paull CK, Taylor LT, Sylva SP, Hayes JM, DeLong EF (2001) Comparative analysis of methane-oxidizing archaea and sulfate-reducing bacteria in anoxic marine sediments. Appl Environ Microbiol 67:1922-1934

Oude Elferink SJWH, Vorstman WJC, Sopjes A, Stams AJM (1998) Characterization of the sulfate-reducing and syntrophic population in granular sludge from a full-scale anaerobic reactor treating papermill wastewater. FEMS Microbiol Ecol 27:185-194

Overmann J (2002) Phototrophic consortia: a tight cooperation between nonrelated eubacteria. In: Seckbach J (ed) Symbiosis: mechanisms and model systems. Kluwer, Dordrecht, pp 239-255

Pancost RD, Damsté JSS, de Lint S, van der Maarel MJEC, Gottschal KC, The Medinaut Shipboard Scientific Party (2000) Biomarker evidence for widespread anaerobic methane oxidation in Mediterranean sediments by a consortium of methanogenic archaea and bacteria. Appl Environ Microbiol 66:1126-1132

Pfennig N (1980) Syntrophic mixed cultures and symbiotic consortia with phototrophic bacteria: a review. In: Gottschalk G, Pfennig N, Werner H (eds) Anaerobes and anaerobic infections. Fischer, Stuttgart/New York, pp 127-131 
Phelps TJ, Zeikus JG (1984) Influence of $\mathrm{pH}$ on terminal carbon metabolism in anoxic sediments from a mildly acidic lake. Appl Environ Microbiol 48:1088-1095

Platen H, Schink B (1987) Methanogenic degradation of acetone by an enrichment culture. Arch Microbiol 149:136-141

Platen H, Janssen PH, Schink B (1994) Fermentative degradation of acetone by an enrichment culture in membrane-separated culture devices and in cell suspensions. FEMS Microbiol Lett 122:27-32

Plugge CM, Stams AJM (2001) Arginine catabolism by Thermanaerovibrio acidaminovorans. FEMS Microbiol Lett 195:259-262

Plugge CM, Dijkema C, Stams AJM (1993) Acetyl-CoA cleavage pathway in a syntrophic propionate oxidizing bacterium growing on fumarate in the absence of methanogens. FEMS Microbiol Lett 110:71-76

Plugge CM, Zoetendal EG, Stams AJM (2000) Caloramator coolhaasii, sp. nov. a glutamate-degrading, moderately thermophilic anaerobe. Int J Syst Bacteriol 50:1155-1162

Plugge CM, van Leeuwen JM, Hummelen T, Balk M, Stams AJM (2001) Elucidation of the pathways of catabolic glutamate conversion in three thermophilic anaerobic bacteria. Arch Microbiol 176:29-36

Plugge CM, Balk M, Zoetendal EG, Stams AJM (2002) Gelria glutamica, gen. nov., sp. nov., a thermophilic obligate syntrophic glutamate-degrading anaerobe. Int J Syst Evol Microbiol 52(Pt 2):401-407

Reeburgh WS (1980) Anaerobic methane oxidation: rate distributions in Skan Bay sediments. Earth Planet Sci Lett 47:345-352

Roeder J, Schink B (2009) Syntrophic degradation of cadaverine by a defined methanogenic coculture. Appl Environ Microbiol 75:4821-4828

Roy F, Samain E, Dubourgier HC, Albagnac G (1986) Syntrophomonas sapovorans sp. nov., a new obligately proton reducing anaerobe oxidizing saturated and unsaturated long chain fatty acids. Arch Microbiol 145:142-147

Santegoeds CM, Damgaard LR, Hesselink G, Zopfi J, Lens P, Muyzer G, de Beer D (1999) Distribution of sulfate-reducing and methanogenic bacteria in anaerobic aggregates determined by microsensor and molecular analyses. Appl Environ Microbiol 65:4618-4629

Schink B (1984) Fermentation of 2.3-butanediol by Pelobacter carbinolicus sp. nov., and Pelobacter propionicus, sp. nov., and evidence for propionate formation from $\mathrm{C}_{2}$ compounds. Arch Microbiol 137:33-41

Schink B (1985a) Fermentation of acetylene by an obligate anaerobe, Pelobacter acetylenicus sp. nov. Arch Microbiol 142:295-301

Schink B (1985b) Mechanism and kinetics of succinate and propionate degradation in anoxic freshwater sediments and sewage sludge. J Gen Microbiol 131:643-650

Schink B (1990) Conservation of small amounts of energy in fermenting bacteria. In: Finn RK, Prave P (eds) Biotechnology: focus 2. Hanser, New York, pp 63-89

Schink B (1991) Syntrophism among prokaryotes. In: Balows A, Truper HG, Dworkin M, Schleifer KH (eds) The prokaryotes, 2nd edn. Springer, New York, pp 276-299

Schink B (1994) Diversity, ecology, and isolation of acetogenic bacteria. In: Drake HL (ed) Acetogenesis. Chapman and Hall, New York, pp 197-235

Schink B (1997) Energetics of syntrophic cooperations in methanogenic degradation. Microbiol Mol Biol Rev 61:262-280

Schink B, Friedrich M (1994) Energetics of syntrophic fatty acid degradation. FEMS Microbiol Rev 15:85-94

Schink B, Stieb, M (1983) Fermentative degradation of polyethylene glycol by a new strictly anaerobic Gram-negative non-sporeforming bacterium, Pelobacter venetianus sp. nov. Appl Environ Microbiol 45:1905-1913

Schink B, Thauer RK (1988) Energetics of syntrophic methane formation and the influence of aggregation. In: Lettinga G, Zehnder AJB, Grotenhuis JTC Hulshoff LW (eds) Granular anaerobic sludge: microbiology and technology. Pudoc, Wageningen, pp 5-17

Schink B, Philipp B, Muller J (2000) Anaerobic degradation of phenolic compounds. Naturwissenschaften $87: 12-23$

Schnurer A, Houwen FP, Svensson BH (1994) Mesophilic syntrophic acetate oxidation during methane formation by a triculture at high ammonium concentration. Arch Microbiol 162:70-74

Schnurer A, Schink B, Svensson BH (1996) Clostridium ultunense sp. nov., a mesophilic bacterium oxidizing acetate in syntrophic association with a hydrogenotrophic methanogenic bacterium. Int J Syst Bacteriol 46:1145-1152
Schnurer A, Svensson BH, Schink B (1997) Enzyme activities in and energetics of acetate metabolism by the mesophilic syntrophically acetate-oxidizing anaerobe Clostridium ultunense. FEMS Microbiol Lett 154:331-336

Schocke L, Schink B (1997) Energetics of methanogenic benzoate degradation by Syntrophus gentianae in syntrophic coculture. Microbiology 143:2345-2351

Schocke L, Schink B (1998) Membrane-bound proton-translocating pyrophosphatase of Syntrophus gentianae, a syntrophically benzoatedegrading fermenting bacterium. Eur J Biochem 256:589-594

Schocke L, Schink B (1999) Biochemistry and energetics of fermentative benzoate degradation by Syntrophus gentianae. Arch Microbiol 171:331-337

Scholten JCM, Conrad R (2000) Energetics of syntrophic propionate oxidation in defined batch and chemostat cocultures. Appl Environ Microbiol 66:2934-2942

Schonheit P, Moll J, Thauer RK (1980) Growth parameters (Ks, vmax, Ys) of Methanobacterium thermoautotrophicum. Arch Microbiol 127:59-65

Seelert H, Poetsch A, Dencher NA, Engel A, Stahlberg H, Muller DJ (2000) Proton-powered turbine of a plant motor. Nature 405:418-419

Sekiguchi Y, Kamagata Y, Nakamura K, Ohashi A, Harada H (2000) Syntrophothermus lipocalidus gen. nov., sp. nov., a novel thermophilic, syntrophic, fatty-acid-oxidizing anaerobe which utilizes isobutyrate. Int J Syst Evol Microbiol 50:771-779

Stams AJM (1994) Metabolic interactions between anaerobic bacteria in methanogenic environments. Ant v Leeuwenhoek 66:271-294

Stams AJM, Hansen TA (1984) Fermentation of glutamate and other compounds by Acidaminobacter hydrogenoformans gen. nov., sp. nov., an obligate anaerobe isolated from black mud. Studies with pure cultures and mixed cultures with sulfate-reducing and methanogenic bacteria. Arch Microbiol 137:329-337

Stams AJM, Plugge CM (1990) Isolation of syntrophic bacteria on metabolic intermediates. In: Belaich JP, Bruschi M, Garcia JL (eds) Microbiology and biochemistry of strict anaerobes involved in interspecies hydrogen transfer. Plenum, New York, pp 473-476

Stams AJM, Plugge CM (2009) Electron transfer in syntrophic communities of anaerobic bacteria and archaea. Nat Rev Microbiol 7:568-577

Stams AJM, Grotenhuis JTC, Zehnder AJB (1989) Structure-function relationship in granular sludge. In: Hattori T, Ishida Y, Maruyama Y, Morita RY, Uchida A (eds) Recent advances in microbial ecology. Japan Scientific Society Press, Tokyo, pp 440-445

Stams AJM, van Dijk JB, Dijkema C, Plugge CM (1993) Growth of syntrophic propionate-oxidizing bacteria with fumarate in the absence of methanogenic bacteria. Appl Environ Microbiol 59:1114-1119

Stams AJM, Dijkema C, Plugge CM, Lens P (1998) Contribution of ${ }^{13}$ C-NMR spectroscopy to the elucidation of pathways of propionate formation and degradation in methanogenic environments. Biodegradation 9:463-473

Stieb M, Schink B (1985) Anaerobic oxidation of fatty acids by Clostridium bryantii sp. nov., a spore-forming, obligately syntrophic bacterium. Arch Microbiol 140:387-390

Stieb M, Schink B (1986) Anaerobic degradation of isovalerate by a defined methanogenic coculture. Arch Microbiol 144:291-295

Stieb M, Schink B (1989) Anaerobic degradation of isobutyrate by methanogenic enrichment cultures and by a Desulfococcus multivorans strain. Arch Microbiol 151:126-132

Stock D, Leslie AGW, Walker JE (1999) Molecular architecture of the rotary motor in ATP synthase. Science 286:1700-1705

Stumm CK, Gijzen HJ, Vogels GD (1982) Association of methanogenic bacteria with ovine rumen ciliates. Br J Nutr 47:95-99

Svetlitshnyi V, Rainey F, Wiegel J (1996) Thermosyntropha lipolytica gen. nov., sp. nov., a lipolytic, anaerobic, alkalitolerant, thermophilic bacterium utilizing short- and long-chain fatty acids in syntrophic coculture with a methanogenic archaeum. Int J Syst Bacteriol 46:1131-1137

Tarlera S, Stams AJM (1999) Degradation of proteins and amino acids by Caloramator proteoclasticus in pure culture and in coculture with Methanobacterium thermoautotrophicum Z245. Appl Microbiol Biotechnol 53:133-138

Tarlera S, Muxi L, Soubes M, Stams AJM (1997) Caloramator proteoclasticus sp. nov., a new moderately thermophilic anaerobic proteolytic bacterium. Int J Syst Bacteriol 47:651-656 
Thauer RK, Morris JG (1984) Metabolism of chemotrophic anaerobes: old views and new aspects. In: Kelly DP, Carr NG (eds) The microbe 1984. Part II: prokaryotes and eukaryotes. Cambridge University Press, Cambridge, UK, pp 123-168

Thauer RK, Jungermann K, Decker K (1977) Energy conservation in chemotrophic anaerobic bacteria. Bacteriol Rev 41:100-180

Thiele JH, Zeikus JG (1988) Control of interspecies electron flow during anaerobic digestion: significance of formate transfer versus hydrogen transfer during syntrophic methanogenesis in flocs. Appl Environ Microbiol 54:20-29

Tholozan JL, Samain E, Grivet JP, Moletta R, Dubourguier HC, Albagnac G (1988) Reductive carboxylation of propionate to butyrate in methanogenic ecosystems. Appl Environ Microbiol 54:441-445

Tholozan JL, Samain E, Grivet JP, Albagnac G (1990) Propionate metabolism in a methanogenic enrichment culture: direct reductive carboxylation and acetogenesis pathways. FEMS Microbiol Ecol 73:291-298

Thomsen TR, Finster K, Ramsing NB (2001) Biogeochemical and molecular signatures of anaerobic methane oxidation in a marine sediment. Appl Environ Microbiol 67:1646-1656

Valentine DL, Reeburgh WS (2000) New perspectives on anaerobic methane oxidation. Environ Microbiol 2:477-484

Valentine DL, Blanton DC, Reeburgh WS (2000a) Hydrogen production by methanogens under low-hydrogen conditions. Arch Microbiol 174: 415-421

Valentine DL, Reeburgh WS, Blanton DC (2000b) A culture apparatus for maintaining $\mathrm{H}_{2}$ at sub-nanomolar concentrations. J Microbiol Methods 39:243-251

van Bruggen JJA, Stumm CK, Vogels GD (1983) Symbiosis of methanogenic bacteria and sapropelic protozoa. Arch Microbiol 136:89-95

van Bruggen JJA, Stumm CK, Zwart KB, Vogels GD (1985) Endosymbiotic methanogenic bacteria of the sapropelic amoeba Mastigella. FEMS Microbiol Ecol 31:187-192

van Lier JB, Grolle KC, Frijters CT, Stams AJM, Lettinga G (1993) Effects of acetate, propionate, and butyrate on the thermophilic anaerobic degradation of propionate by methanogenic sludge and defined cultures. Appl Environ Microbiol 59:1003-1011

Von Ballmoos C, Wiedenmann A, Dimroth P (2009) Essentials for ATP synthesis by $\mathrm{F}_{1} \mathrm{~F}_{0}$ ATP synthases. Annu Rev Biochem 78:649-672

Wallrabenstein C, Schink B (1994) Evidence of reversed electron transport involved in syntrophic butyrate and benzoate oxidation by Syntrophomonas wolfei and Syntrophus buswellii. Arch Microbiol 162:136-142

Wallrabenstein C, Hauschild E, Schink B (1994) Pure culture and cytological properties of Syntrophobacter wolinii. FEMS Microbiol Lett 123:249-254

Wallrabenstein C, Gorny N, Springer N, Ludwig W, Schink B (1995a) Pure culture of Syntrophus buswellii, definition of its phylogenetic status, and description of Syntrophus gentianae sp. nov. Syst Appl Microbiol 18:62-66

Wallrabenstein C, Hauschild E, Schink B (1995b) Syntrophobacter pfennigii sp. nov., a new syntrophically propionate-oxidizing anaerobe growing in pure culture with propionate and sulfate. Arch Microbiol 164:346-352

Warikoo V, McInerney MJ, Robinson JA, Suflita JM (1996) Interspecies acetate transfer influences the extent of anaerobic benzoate degradation by syntrophic consortia. Appl Environ Microbiol 62:26-32
Widdel F (1988) Microbiology and ecology of sulfate- and sulfur-reducing bacteria. In: Zehnder AJB (ed) Biology of anaerobic microorganisms. Wiley, New York, pp 469-585

Widdel F, Hansen T (1991) The dissimilatory sulfate and sulfur-reducing bacteria. In: Balows A, Truper HG, Dworkin M, Schleifer KH (eds) The prokaryotes, 2nd edn. Springer-Verlag, New York, pp 583-624.

Wildenauer FX, Winter J (1986) Fermentation of isoleucine and arginine by pure and syntrophic cultures of Clostridium sporogenes. FEMS Microbiol Ecol 38:373-379

Winter J, Schindler F, Wildenauer FX (1987) Fermentation of alanine and glycine by pure and syntrophic cultures of Clostridium sporogenes. FEMS Microbiol Ecol 45:153-161

Wofford NQ, Beaty PS, McInerney MJ (1986) Preparation of cell-free extracts and the enzymes involved in fatty acid metabolism in Syntrophomonas wolfei. J Bacteriol 167:179-185

Worm P, Stams AJM, Cheng X, Plugge CM (2011) Growth- and substratedependent transcription of formate dehydrogenase and hydrogenase coding genes in Syntrophobacter fumaroxidans and Methanospirillum hungatei. Microbiology 157:280-289

Wu W-M, Jain MK, Hickey RF, Zeikus JG (1991) Characterization of metabolic performance of methanogenic granules treating brewery wastewater: role of sulfate-reducing bacteria. Appl Environ Microbiol 57:3438-3449

Wu W-M, Hickey RF, Jain M, Zeikus JG (1993) Energetics and regulations of formate and hydrogen metabolism by Methanobacterium formicicum. Arch Microbiol 159:57-65

Wu W-M, Jain MK, Hickey RF, Zeikus JG (1994) Anaerobic degradation of normaland branched-chain fatty acids with four or more carbons to methane by a syntrophic methanogenic triculture. Appl Environ Microbiol 57:2220-2226

Wu W-M, Jain MK, Hickey RF, Zeikus JG (1996) Perturbation of syntrophic isobutyrate and butyrate degradation with formate and hydrogen. Biotechnol Bioeng 52:404-411

Zehnder AJB (1978) Ecology of methane formation. In: Mitchell R (ed) Water pollution microbiology, vol 2. Wiley, London, pp 349-376

Zehnder AJB, Brock TD (1979) Methane formation and methane oxidation by methanogenic bacteria. J Bacteriol 137:420-432

Zehnder AJB, Ingvorsen K, Marti T (1982) Microbiology of methane bacteria. In: Hughes DE, Stafford DA, Wheatley BI, Baader W, Lettinga G, Nyns EJ, Verstraete W (eds) Anaerobic digestion. Elsevier Biomedical Press, Amsterdam, pp 45-68

Zeikus JG, Winfrey M (1976) Temperature limitation of methanogenesis in aquatic sediments. Appl Environ Microbiol 31:99-107

Zhao H, Yang D, Woese CR, Bryant MP (1989) Assignment of Clostridium bryantii to Syntrophospora bryantii gen. nov., nov. comb., based on $16 \mathrm{~S}$ rRNA sequence analysis of its crotonate-grown pure culture. Int J Syst Bacteriol 40:40-44

Zindel U, Freudenberg W, Rieth M, Andreesen JR, Schnell J, Widdel F (1988) Eubacterium acidaminophilum sp. nov., a versatile amino acid-degrading anaerobe producing or utilizing $\mathrm{H}_{2}$ or formate: description and enzymatic studies. Arch Microbiol 150:254-266

Zinder SH, Koch M (1984) Non-aceticlastic methanogenesis from acetate: acetate oxidation by a thermophilic syntrophic coculture. Arch Microbiol 138:263-272 